\title{
The homeodomain factor Gbx1 is required for locomotion and cell specification in the dorsal spinal cord
}

Dorsal horn neurons in the spinal cord integrate and relay sensory information to higher brain centers. These neurons are organized in specific laminae and different transcription factors are involved in their specification. The murine homeodomain Gbx1 protein is expressed in the mantle zone of the spinal cord at E12.5-13.5, correlating $\mathrm{w}$ ith the appearance of a discernable dorsal horn around E14 and eventually defining a narrow layer in the dorsal horn around perinatal stages. At postnatal stages, Gbx1 identifies a specific subpopulation of GABAergic neurons in the dorsal spinal cord. We have generated a loss of function mutation for Gbx 1 and analyzed its consequences during spinal cord development. Gbxl -/- mice are viable and can reproduce as homozygous null mutants. However, the adult mutant mice display an altered gait during forward movement, that specifically affects the hindlimbs. This abnormal gait was evaluated by a series of behavioral tests, indicating that locomotion is impaired, but not muscle strength or motor coordination. Molecular analysis showed that the development of the dorsal horn is not profoundly affected in Gbxl-/- mutant mice. However, analysis of terminal neuronal differentiation revealed that the number of GABAergic inhibitory interneurons in the superficial dorsal horn is diminished. Our study unveiled a role for Gbxl in specifying a subset of GABAergic neurons in the dorsal horn of the spinal cord involved in the control of posterior limb movement. 


\section{The homeodomain factor Gbx1 is required for locomotion and cell specification in the dorsal spinal cord}

4 Hamid Meziane ${ }^{1 *}$, Valérie Fraulob ${ }^{2}$, Fabrice Riet ${ }^{1}$, Wojciech Krezel ${ }^{2}$, Mohammed Selloum ${ }^{1}$,

5 Michaela Geffarth ${ }^{3}$, Dario Acampora ${ }^{4}$, Yann Hérault ${ }^{1}$, Antonio Simeone ${ }^{4}$, Michael Brand ${ }^{3}$,

6 Pascal Dollé ${ }^{2 \#}$ and Muriel Rhinn ${ }^{2 \# @ ~}$

$7{ }^{1}$ Mouse Clinical Institute/Institut Clinique de la Souris (MCI/ICS), PHENOMIN, GIE CERBM, 81 rue Laurent Fries, 67404 Illkirch Cedex, France

$9{ }^{2}$ Institut de Génétique et de Biologie Moléculaire et Cellulaire, Centre National de la Recherche 10 Scientifique (UMR 7104), Institut National de la Santé et de la Recherche Médicale (U 964), 11 Université de Strasbourg, 1 rue Laurent Fries, 67404 Illkirch Cedex, France

$12{ }^{3}$ DFG-Center for Regenerative Therapies / Cluster of Excellence (CRTD), and Biotechnology 13 Center, Technische Universität Dresden, Fetscherstr. 105, 01307, Dresden, Germany

$14{ }^{4}$ Institute of Genetics and Biophysics "A. Buzzati Traverso" CNR; Via P. Castellino 111, 80131, Naples 15 and CEINGE Biotecnologie Avanzate Via G. Salvatore, 482

1680145 Naples, and SEMM European School of Molecular Medicine - Naples site

17 Key words: spinal cord, Gbx genes, GABAergic neurons, locomotion, mouse mutant

18 Running title: Phenotypic analysis of $G b x 1^{-1-}$ mouse mutants

$19 *$ These authors have equally contributed to this study

20 " Senior authors

$21 @$ Correspondence should be addressed to: Muriel Rhinn (Tel: +33 388653 342; Fax: +33 388

22653 201; E-mail: rhinn@igbmc.fr) 


\section{Abstract}

24 Dorsal horn neurons in the spinal cord integrate and relay sensory information to higher brain 25 centers. These neurons are organized in specific laminae and different transcription factors are 26 involved in their specification. The murine homeodomain Gbx1 protein is expressed in the 27 mantle zone of the spinal cord at E12.5-13.5, correlating with the appearance of a discernable dorsal horn 28 around E14 and eventually defining a narrow layer in the dorsal horn around perinatal stages. At postnatal stages, Gbx1 identifies 29 a specific subpopulation of GABAergic neurons in the dorsal spinal cord. We have generated a loss of function mutation for Gbx 1

30 and analyzed its consequences during spinal cord development. Gbxl-/- mice are viable and can reproduce as 31 homozygous null mutants. However, the adult mutant mice display an altered gait during forward movement, that 32 specifically affects the hindlimbs. This abnormal gait was evaluated by a series of behavioral tests, indicating that 33 locomotion is impaired, but not muscle strength or motor coordination. Molecular analysis showed that the development of the dorsal 34 horn is not profoundly affected in Gbx1-/- mutant mice. However, analysis of terminal neuronal differentiation revealed that the proportion of 35 GABAergic inhibitory interneurons in the superficial dorsal horn is diminished. Our study unveiled a role for Gbxl in specifying a subset of 36 GABAergic neurons in the dorsal horn of the spinal cord involved in the control of posterior limb movement. 
38 Perception of sensory inputs from both external and internal environments requires multiple

39 levels of organization in the nervous system. The dorsal spinal cord plays critical roles in 40 organizing responses to sensory input, and contains neurons that relay somatosensory information 41 from sensory neurons in the periphery to motor neurons located in the ventral horns and to higher 42 brain centers (for review: Helms \& Johnson 2003). These functions reside in a large number of 43 distinct interneuron types that are arranged in an organized laminar structure in the dorsal horns 44 (Rexed 1952; Brown 1981). Five parallel layers (laminae) have been defined in the murine spinal 45 cord dorsal horn. These laminae are formed of unique combination of neurons, distinguished by their morphology and projections and by their gene expression profiles. The laminae receive different sensory input, with tactile perception mediated by myelinated axon bundles projecting to internal dorsal laminae (III, IV, V), and pain and temperature conveyed through unmyelinated axons that project to more superficial laminae (I, II) (for review: Caspary \& Anderson 2003). Proprioception is mediated by sensory neurons that project through the dorsal spinal cord to an intermediate zone which in turn projects to the ventral spinal cord where a direct connection is made with motoneurons (Brown, 1981; for review: Caspary \& Anderson 2003).

There are six early-born (in the mouse, by embryonic day E10-12.5) dorsal neuron populations called dI1-dI6 and two late-born (E11-E13) populations called dILA and dILB, defined by expression of specific homeodomain transcription factors (for review: Helms \& Johnson 2003, Lewis 2006). These neurons can be further classified by their dependance on roof plate signaling for formation: class A (dI1-dI3) neurons depend on, whereas class B (dI4-dI6, dILA/B) neurons are independent of roof plate signals (Gross, Dottori \& Goulding 2002; Müller et al. 2002; for review: Helms \& Johnson 2003). The dorsal interneuron subtypes dI1-3 migrate ventrally, whereas a subset of dI4 and dI5 cells migrate laterally to populate the deep dorsal horn (laminae IV-V). The dILA/B subclasses migrate to the superficial dorsal laminae (I-III), and mediate pain and temperature sensitive circuits (for review: Caspary \& Anderson 2003).

The functional architecture of the mature dorsal horn is the result of developmental processes that involve cell-type specification and differentiation, as well as cell migration. Several events that control the specification of various neuronal subtypes in the spinal cord have been defined in recent studies (for reviews: Lee \& Jessell 1999; Briscoe \& Ericson, 1999; Caspary \& Anderson 

central role during development of neurons in the dorsal horn (for reviews: Goulding et al. 2002; Helms \& Johnson 2003). Relatively few direct correlations have been made between dorsal interneuron progenitor classes and terminally differentiated cell types. However, formation of the proprioceptor pathway, which projects through the dorsal horn to the ventrally located motor neurons (Brown 1981; Willis \& Coggeshall 1991) was shown to be dependent on Math1 (Bermingham et al. 2001; Gowan et al. 1991). Also, a dorsal horn-specific transcription factor, Drg11, is expressed in late born cells derived from d15 precursors and is required for correct afferent fiber projections of nociceptive sensory neurons and correct dorsal horn morphogenesis (Chen et al. 2001; Rebelo et al. 2010). Finally, the Lbxl gene is required for maturation of several dorsal horn cell types which later populate laminae I-III, and is critical for the correct projection of the nociceptive fibers into these laminae (Gross, Dottori \& Goulding 2002; Müller et al. 2002).

The gene encoding the homeodomain factor Gbx1 is expressed broadly in the mantle zone of the spinal cord at E12.5-13.5 (Rhinn et al. 2004 ; Waters et al. 2003 ; John, Wildner \& Britsch 2005). With the appearance of a discernable dorsal horn around E14, Gbxl expression becomes more restricted, eventually defining a narrow layer in the dorsal horn around perinatal stages (John, Wildner \& Britsch 2005). Recently, immunohistological analysis showed that at E12.5, only a subpopulation of the Lbx1-positive cells coexpress Gbx1 (John, Wildner \& Britsch 2005). Lbx1 is a key determinant for the specification of class B neurons (Gross, Dottori \& Goulding 2002; Müller et al. 2002), suggesting that Gbx1-positive cells could correspond to class B neuron precursors (John, Wildner \& Britsch 2005). Late-born class B neurons comprise initially two neuron populations, dILA and dILB, which are born in an apparent salt and pepper pattern in the dorsal spinal cord. dILA neurons express Lbxl, Pax2, and Lhx1/5, whereas dILB cells express Lbx1, Lmxlb, and Tlx3 (Müller et al. 2002). At E12.5 and E14.5, Gbx1 neurons co-express the transcription factors Lhx1/5 and Pax2, but are negative for Lmx1b and Tlx3. This indicates that Gbx1 expression distinguishes a subpopulation of dILA neuronal cells (John, Wildner \& Britsch 2005). Furthermore, these authors show that GABA or Gad67 expressing neurons coexpress Gbx1, suggesting that Gbx1-positive cells may differentiate into GABAergic neurons.

To investigate the function of Gbx1 during dorsal horn development, we have generated mice bearing a mutation that ablates Gbx1 function. We report that Gbxl knockout mice are viable and can reproduce as homozygous null mutants. However, the adult mutant mice display an altered gait during forward movement that specifically affects hindlimbs. This abnormal gait was evaluated by a series of behavioral tests, which revealed that locomotion is impaired, but not muscle strength or motor coordination. We then analyzed the development of the spinal cord dorsal horn in Gbxl-/- mice. Despite the clear behavioral phenotype, we did not observe changes in the expression of homeodomain factors regulating dorsal spinal cord development, suggesting that development of the dorsal horn is not profoundly affected in Gbxl-/- mice. However, analysis of terminal neuronal differentiation revealed that expression of Gad67, a marker for GABAergic inhibitory interneurons, is diminished. Gbx1 is therefore required for the differentiation of inhibitory local circuit interneurons in the superficial dorsal horn, demonstrating a function for this transcription factor in the dorsal horn of the spinal cord. 


\section{Tissue collection and sample preparation} entire homeodomain (Fig. 1A). recombination was 7 out of 350 clones analyzed.

\section{Generation and genotyping of chimeric and mutant mice} resulting in a nearly pure genetic background. stored at $-80^{\circ} \mathrm{C}$ until use.

Gbxl cDNA fragment previously characterized (Rhinn et al. 2004). A Gbxl loss of function mutation was produced by homologous recombination in embryonic stem cells (Ramìrez-Solis, Davis \& Bradley 1993). The targeting vector contained a 5.4 kb XmnI fragment (upstream arm), ending $33 \mathrm{bp}$ upstream of the homeodomain sequence located in Gbxl second exon, and a $1.6 \mathrm{~kb}$ KpnI fragment (downstream arm), whose sequence started $91 \mathrm{bp}$ downstream from the homeodomain. These fragments were excised from the recombinant phage and cloned in the mutagenesis pGN vector (Le Mouellic, Lallemand \& Brûlet 1990) to generate the pGNGbxl targeting vector (Fig. 1A). In this vector, the fragments are inserted on each side of a lacZ reporter gene and a neomycin resistance gene, and their insertion by homologous recombinaton in the Gbxl gene will generate a 313 bp deletion encompassing the

\section{Transfection of embryonic stem cells and selection of targeted clones}

HM-1 embryonic stem (ES) cells (Magin, Whir \& Melton 1992) were cultured on neomycin-resistant mouse embryonic fibroblasts, as described in Robertson, 1987. Ten $\mu \mathrm{g}$ of the pGN-Gbxl targeting vector were linearized by digestion of the unique NotI restriction site, and electroporated into $2 \times 10^{7} \mathrm{ES}$ cells resuspended in $750 \mu \mathrm{l} \mathrm{HeBS}$ medium $(20 \mathrm{mM}$ Hepes $\mathrm{pH} 7.05,137 \mathrm{mM}$ $\mathrm{NaCl}, 5 \mathrm{mM} \mathrm{KCl}, 0.7 \mathrm{mM} \mathrm{Na}_{2} \mathrm{HPO}_{4}, 6 \mathrm{mM}$ glucose), at $200 \mathrm{~V}, 960 \mu \mathrm{F}$. Positive selection was carried out for 11 days with 350 $\mu \mathrm{g} / \mathrm{ml} \mathrm{G418}$. Resistant colonies were picked and DNA was extracted from a fraction (1/5) of the cells to perform Southern blot analysis to identify homologous recombination events. The probe used is an external fragment located immediately downstream to the targeting vector (Fig. 1A,B). Positive clones were expanded before freezing. The frequency of homologous

After thawing, 10 to $15 \mathrm{ES}$ cells were microinjected into blastocysts collected at E3.5 from C57BL/6 females mated with C57BL/6 males (for procedures: Nagy et al. 2003). Injected blastocysts were reimplanted in the uterine horn of pseudopregnant recipient females. Chimeric animals were back-crossed to C57BL/6J mice and germ-line transmission was scored by the presence of agouti coat pigmentation. Heterozygous offspring were identified by PCR genotyping. Tail tips were incubated in lysis buffer (50 mM Tris pH 8.0, $100 \mathrm{mM}$ EDTA, $100 \mathrm{mM} \mathrm{NaCl}, 1 \%$ SDS, $0.6 \mathrm{mg} / \mathrm{ml}$ proteinase $\mathrm{K}$ ) overnight at $55^{\circ} \mathrm{C}$, phenol-chloroform extracted, ethanol precipitated and redissolved in $10 \mathrm{mM}$ Tris- $\mathrm{HCl}, 1 \mathrm{mM}$ EDTA pH 8.0 at a final concentration of $0.2-1.0 \mu \mathrm{g} / \mu \mathrm{l}$ The presence of a wild-type or mutated allele was detected using three primers: a sense primer F1: 5'GGTGACAGCGAGGACAGCTTCCT-3', an antisense primer R1: 5'-CCCAGAACGACTGCTCACATTGC-3', and an antisense primer LacZ R2: 5'-GGCCTCTTCGCTATTACGCCA-3'. The presence of a wild-type allele was detected using the F1/R1 primers which amplify a $354 \mathrm{bp}$ fragment. The presence of a mutated allele was detected by using the F1/LacZ R2 primers which amplify a $269 \mathrm{bp}$ fragment. Thirty cycles (denaturation: $1 \mathrm{~min}, 95^{\circ} \mathrm{C}$, annealing : $1 \mathrm{~min}, 62^{\circ} \mathrm{C}$; elongation : $30 \mathrm{~s}, 74^{\circ} \mathrm{C}$ ) were performed, and the amplified products were separated by $2 \%$ agarose gel electrophoresis (Fig. 1C). Phenotypic and molecular analyses were performed after several generations of backcrosses (>5) to C57BL/6J mice,

Pregnant females obtained from natural matings (morning of vaginal plug was considered as E0.5) were sacrificed and fetuses were collected in phosphate-buffered saline $\left(\mathrm{NaCl}: 8.01 \mathrm{~g} / \mathrm{L}, \mathrm{KCl}: 0.2 \mathrm{~g} / \mathrm{L}, \mathrm{Na}_{2} \mathrm{HPO}_{4}, 2 \mathrm{H}_{2} \mathrm{O}: 1.78 \mathrm{~g} / \mathrm{L}, \mathrm{KH}_{2} \mathrm{PO}_{4}: 0.27 \mathrm{~g} / \mathrm{L}, \mathrm{pH} 7.5\right.$; hereafter abbreviated PBS 1x) after cesarean section. The specimens were dissected, fixed overnight in $4 \%$ paraformaldehyde (PFA) diluted in PBS 1x, pH 7.5, cryoprotected in 20\% sucrose in PBS 1x, pH 7.5 and embedded in Shandon Cryomatrix (Thermo Electron Corperation) before freezing at $-80^{\circ} \mathrm{C}$. Cryosections $(14 \mu \mathrm{m}$ thickness, Leica CM3050S cryostat) sections were made in a coronal plane, collected on Superfrost slides, and 
For whole-mount immunostaining or in situ hybridization, embryos were fixed overnight in $4 \%$ PFA, dried at room temperature, and stored at -20 ${ }^{\circ} \mathrm{C}$ in $100 \%$ methanol.

\section{In situ hybridization}

In situ hybridization was performed with digoxigenin-labeled probes as previously described (Chotteau-Lelièvre et al. 2006). Template DNAs were kindly provided by Drs K. Jagla (Lbxl), C. Birchmeier (Lmxlb), M. Tessier-Lavigne (Netrin), A.J. Tobin (Gad67) and P. Gruss (Pax2), P. Bouillet (Gbx2), B. Giros (Slc17a6), F. Chen (Drg11), R. Krumlauf (Hoxb1), and F. Rijli (Hoxa2). For all experiments 3 animals of each genotype, from 2 or more independent litters, were analyzed (except for Gbx2: Fig. S1A-D, n=2). Cell countings were performed in the dorsal horn (Gad67, Pax2, Slc17a6) or ventral horn (Islet1) on 3 transverse sections for each animal, at comparable levels of the lumbar spinal cord (all sections were collected serially, with section planes being separated by $112 \mu \mathrm{m}$ ). Three animals of each genotype were thus analyzed for each marker.

All expression patterns were documented using a macroscope (Leica M420) or microscope (DM4000B, objective 10x), both connected to a Photometrics camera with the CoolSNAP (v. 1.2) imaging software (Roger Scientific, Chicago, IL). Cell counts were performed using the image $\mathrm{J}(\mathrm{NIH} 1.45 \mathrm{~S})$ software. Blue labelled cells and unlabelled cells were counted manually with the cell counter plugin. Three sections separated by $112 \mu \mathrm{m}$ in 3 independent embryos were counted for each condition, and statistical significance of cell counts was validated with a two way measures analysis of variance (ANOVA) with the first variable as fixed effect (i.e. genotype) and a second variable as random effect of repeat observations on the same individual. The level of significance was set at $p<0.05$. Graphs represent averages of counting values and SEM.

\section{Immunohistochemistry}

After antigen unmasking in citrate buffer $0.01 \mathrm{M}\left(\mathrm{pH}\right.$ 6) during $15 \mathrm{~min}$ in a microwave oven, sections were treated in $\mathrm{H}_{2} \mathrm{O}_{2} 3 \%$ in $\mathrm{PBS} 1 \mathrm{x}$, $\mathrm{pH} 7.5$ for 5 min, rinsed in PBS $1 \mathrm{x}$, then blocked in PBS $1 \mathrm{x}, \mathrm{pH} 7.5$ containing $0.25 \%$ Triton-X100, 5\% normal goat serum and incubated overnight at $4{ }^{\circ} \mathrm{C}$ with rabbit antiGbx1 (kindly provided by Dr S. Britsch; 1:500), rabbit anti-calbindin D-28K (Chemicon, 1:1000), rabbit anti-Peripherin (Chemicon, 1:500), or mouse anti-Islet1 (40.2D6, concentrated, Developmental Studies Hybridoma Bank, Iowa City, IA, 1:100) in PBS 1x, pH 7.5 containing 0.25\% Triton-X100, 5\% normal goat serum followed by species-specific biotin-coupled secondary antibodies (1:400, Jackson Laboratories) diluted in PBS 1x, pH 7.5. Detection was performed using a Vectastain Elite ABC Kit, following the manufacturer's instructions. Nissl staining was performed by incubation in $0.5 \%$ cresyl violet in water for 15 min. Tunel was performed using the APOPTAG® Peroxidase In Situ Apoptosis detection kit (Millipore). For all experiments 3 animals of each genotype were analyzed.

\section{Behavioral phenotyping procedures}

Cohorts of 10 week-old male and female Gbxl-/- mice in a C57BL/6J genetic background (7 males and 8 females), with their wild-type (WT, 10 males and 9 females) counterparts, were used in this study. Mice were group housed and allowed 2 weeks acclimation in the phenotyping area with controlled temperature $\left(21-22^{\circ} \mathrm{C}\right)$ under a $12-12 \mathrm{~h}$ light-dark cycle (lights on $\left.7 \mathrm{am}-7 \mathrm{pm}\right)$, 
with food and water available ad libitum. Testing started at 10 weeks of age, and all procedures were carried out in accordance with European institutional guidelines. Behavioral tests were performed successively for each cohort of mice, during the light phase of the circadian cycle, according to a pipeline established by the European Mouse Disease Clinic (EUMODIC pipeline 2), by trained experimenters familiar with observation of normal gait patterns in mice. Detailed procedures for each test are available at the URL: http://www.empress.har.mrc.ac.uk/viewempress/index.php? pipeline $=$ EUMODIC+Pipeline +2 .

Neurological examination: General health and basic sensory motor functions were evaluated using a modified SHIRPA protocol (Brown, Chambon \& Hrabé de Angelis 2005; protocol at http://www.empress.har.mrc.ac.uk/viewempress/index.php? pipelineprocedure=EUMODIC+Pipeline+2 Modified+SHIRPA). This analysis is adapted from the procedure developed by Irwin (1968) and from the SHIRPA protocol (Hatcher et al. 2001). It provides an overview of physical appearance, body weight, neurological reflexes and sensory abilities.

Rotarod test: This test evaluates motor coordination and balance by measuring the ability of animals to maintain balance on a rotating rod (Bioseb, Chaville, France). Mice were given three testing trials during which the rotation speed accelerated from 4 to 40 rounds per $\min (\mathrm{rpm})$ over $5 \mathrm{~min}$. Trials were separated by 5-10 min intervals. The average latency (time to fall from the rotating rod) of the three trials was used as index of motor coordination performance.

Grip test: This test measures the maximal muscle strength (g) using an isometric dynamometer connected to a grid (Bioseb). Mice were allowed to grip the grid either with the forepaws or with both the forepaws and hindpaws, then were pulled backwards until they released the grid. Each mouse was submitted to 3 consecutive trials immediately after the modified SHIRPA procedure. The maximal strength developed by the mouse before releasing the grid was recorded and the average value of the three trials was adjusted to body weight.

Beam walking: This test is used to evaluate fine motor coordination and proprioceptive function. The apparatus used is a $2 \mathrm{~cm}$ diameter and $110 \mathrm{~cm}$ long wooden beam, elevated $50 \mathrm{~cm}$ above the ground. A goal box $(12 \times 12 \times 14 \mathrm{~cm})$ is attached at one extremity of the beam. Animals were first habituated to the goal box for $1 \mathrm{~min}$. They were then submitted to 3 training trials during which they were placed at different points of the beam, with the head directed to the goal box, and allowed to walk the corresponding distance to enter the goal box.

After training, animals were submitted to 3 testing trials during which they were placed at the extremity of the beam opposite to the goal box and allowed to walk the beam distance and enter the goal box. The latency to enter the goal box and the number of slips (when one or both hindpaws slipped laterally from the beam) were measured.

Hot plate test: The mice were placed into a glass cylinder on a hot plate (Bioseb) adjusted to $52^{\circ} \mathrm{C}$, and the latency of the first pain reaction of any hindlimb (licking, flinches) was recorded, with a maximum of $30 \mathrm{~s}$ testing.

Electrophysiological measurements: Electrophysiological recordings were performed under ketamine-xylazine anesthesia (100 and $10 \mathrm{mg} / \mathrm{kg}$ body weight, respectively) using a Key Point electromyograph apparatus (Medtronic, France). Disposal scalp needle electrodes were used (ref 9013R0312, Medtronic). The body temperature was maintained at $37^{\circ} \mathrm{C}$ with a homeothermic blanket (Harvard, Paris, France). For measuring the sensory nerve conduction velocity (SNCV), recording electrodes were inserted at the proximal part of the tail and stimulating electrodes placed $20 \mathrm{~mm}$ from the recording needles towards the extremity of the tail. A ground needle electrode was inserted between the stimulating and recording electrodes. Caudal nerve was stimulated with a series of 20 pulses of $0.2 \mathrm{~ms}$ duration at a supramaximal intensity of $8 \mathrm{~mA}$. The average response is included for statistical analysis. The compound muscle action potential (CMAP) was measured in gastrocnemius muscle after sciatic nerve stimulation. For this purpose, stimulating electrodes were placed at the level of the sciatic nerve at $1 \mathrm{~cm}$ from the vertebral column, and recording electrodes placed in the gastrocnemius muscle. A ground needle was inserted in the contralateral paw. The sciatic nerve was stimulated with a single $0.2 \mathrm{~ms}$ pulse at a supramaximal intensity of $8 \mathrm{~mA}$. The amplitude $(\mathrm{mV})$ and the distal latency of the responses (ms) were measured. 
Anxiety-related behavior - open field test: Mice were tested in automated open fields (Panlab, Barcelona, Spain), each virtually divided into central and peripheral regions. The open fields were placed in a room homogeneously illuminated at 150 Lux. Each mouse was placed in the periphery of the open field and allowed to explore freely the apparatus for 20 min, with the experimenter out of the animal's sight. The distance traveled, the number of rears, and time spent in the central and peripheral regions were recorded over the test session. The latency and number of crosses into as well as the percent time spent in center area are used as index of emotionality/anxiety.

Sensorimotor gating - auditory startle reflex reactivity and pre-pulse inhibition (PPI): Acoustic startle reactivity and pre-pulse inhibition of startle were assessed in a single session using standard startle chambers (SR-Lab Startle Response System, San Diego Instruments). Ten different trial types were used: acoustic startle pulse alone (110 db), eight different prepulse trials in which either $70,75,85$ or $90 \mathrm{~dB}$ stimuli were presented alone or preceding the pulse, and finally one trial (NOSTIM) in which only the background noise $(65 \mathrm{~dB})$ was presented to measure the baseline movement in the Plexiglas cylinder. In the startle pulse or prepulse alone trials, the startle reactivity was analyzed, and in the prepulse plus startle trials the amount of PPI was measured and expressed as percentage of the basal startle response.

Statistical analyses: Data were analyzed using unpaired Student t-test, one way or repeated measures analysis of variance (ANOVA) with one between factor (genotype) and one within factor (time). Qualitative parameters (i.e. some of the clinical observations) were analyzed using $\chi^{2}$ test. The level of significance was set at $\mathrm{p}<0.05$.

\section{Animal ethics statement}

Animal experimentation protocols were reviewed and approved by the Direction Départementale des Services Vétérinaires (agreement \#67-172 to H.M., 67-189 to P.D., and institutional agreement \#D67-218-5 for animal housing) and conformed to the NIH and European Union guidelines, provisions of the Guide for the Care and Use of Laboratory Animals, and the Animal Welfare Act.

\section{Results and discussion}

\section{Gbx1-deficient mice are viable, but display a typical duck-like gait}

A loss of function allele for the Gbxl gene was generated by homologous recombination in murine embryonic stem cells (see Materials and Methods). The mutated Gbxl allele is devoid of the entire homeodomain-coding sequence and $\sim 100$ adjacent nucleotides (Fig. 1A-C). After generation of germ-line transmitting chimeras, heterozygous mutant mice ( $G b x 1+/-)$ were found to be viable, fertile and apparently normal. After intercrossing Gbx1+/- mice, Gbxl-/- mutants (generated in a C57BL/6J genetic background) were born in the expected mendelian ratio. Immunohistochemistry performed with an anti-Gbx1 antibody confirmed the absence of detectable Gbx1 protein in the spinal cord of E18.5 Gbx1-/- mutants (Fig. 1D,E). We also checked the expression of Gbx2 from E12.5 to E18.5 (Fig. S1) to exclude a potential compensatory expression due to the loss of function of Gbx1. A subtle increase of Gbx2 mRNA expression might occur in spinal cord cells of $G b x 1-/-$ mice at E12.5-14.5, however this increase was no longer detected at E16.5 or E18.5 (Supplementary material, Fig. S1). This subtle Gbx2 increase could partially compensate for the loss of Gbx1, leading to the absence of phenotypic abnormalities at early developmental stages. Interestingly, when observed by 10 weeks of age, most mutants displayed a typical, unevenness in walking ("duck-like") gait (Fig. 2 and Supplementary material: movie). Both male and female Gbxl-/- mice were fertile and had a normal life span.

General health and sensorimotor abilities in adult $G b x 1$ mutants 
Gbxl-/- males and females had a normal body weight (Table 1) and a normal overall physical appearance. However, many of the Gbxl-/- mutants showed significantly abnormal gait $\left(\chi^{2} \geq 5.20, \mathrm{p}<0.05\right)$. Indeed, $43 \%$ of $G b x 1$ mutant males and $63 \%$ of $G b x 1$ mutant females displayed lack of fluidity in movement, and limping related to hyper-flexion followed by hyper-extension of one or both hindpaws (Table 1; Fig. 2; Supplementary material: movie). Gbx1-/- males and females also showed significantly reduced short-term locomotor activity following immediate transfer for the modified SHIRPA test, as compared to WT counterparts ( $\mathrm{t} \geq 3.46, \mathrm{p}<0.01)$ (Table 1). The other features of general health and basic neurological reflexes were not affected in $G b x l$ mutants.

When tested for specific motor abilities, motor coordination performance measured in the rotarod test $(t \leq 1.29$, NS) and the muscle strength (grid grip) test ( $\mathrm{t} \leq 1.38$, NS) were not affected in Gbx1-/- males and females (Table 1). In the beam walking test, the latency to cross the beam was increased $\left(\mathrm{t}_{15}=3.71, \mathrm{p}<0.01\right.$ for females; non significant for males) and the number of slips was slightly increased (even if not significantly), especially in Gbxl-/- females (Fig. 3). In the open field test, there was a significant effect of genotype concerning locomotor activity $[\mathrm{F}(1,30)=6.51, \mathrm{p}<0.05]$, reflecting reduced locomotion in all Gbx1-/- animals. When considering each gender separately, both Gbxl-/- males and females tended to have reduced locomotor activity over the testing period (although not statistically significant, p=0.09) (Fig. 4). The average speed during motion was also significantly lower in Gbx1-/- males and females than in WT ( $\mathrm{t} \geq 3.36, \mathrm{p}<0.01)$ (Fig. 4). The number of entries into, and the percentage of time spent in, the center of the arena also differed between genotypes $[\mathrm{F}(1,30) \geq 14.48, \mathrm{p}<0.001]$. Both $G b x 1$ - - males and females had significantly decreased number of entries and spent less time in the center of the open field than WT counterparts $(t \geq 2.62$, $p<0.05)$ (Fig. 4), which might reflect increased anxiety in Gbxl-/- mutants. The reduced exploration of the center might also be due to the observed reduced locomotor activity of Gbxl-/- mutants. Altogether, these data show that Gbxl-/- mutant mice have a clear defect in locomotion, although this defect does not appear to result from a coordination problem or a muscle strength deficiency.

To test whether ablation of Gbx1 could affect sensory response, we measured the response of Gbxl mutant mice in a hot plate test. The withdrawal latency was higher in Gbxl-/- males (but not in females) than in WT $\left(\mathrm{t}_{15}=2.10, \mathrm{p}=0.05\right)$ (Table 1), suggesting reduced thermal pain sensitivity in Gbxl mutant males.

The consequence of $G b x l$ inactivation on acoustic startle and pre-pulse inhibition of startle reflex was also evaluated. Regardless of gender, the startle reactivity was comparable between WT and Gbx1-/- mice for all the acoustic stimuli including the startling pulse [Genotype $\mathrm{F}(1,30) \unlhd 0.83$, Sex $\mathrm{F}(1,30) \unlhd 0.85$, Genotype*Sex $\mathrm{F}(1,30) \leq 1.11$, NS] (Fig. 5). When the startling pulse was preceded with prepulses with lower intensities, the PPI level was also comparable between genotypes [Genotype $F(1,30)=0.55$, Sex $F(1,30)=0.32$, Genotype*Sex $F(1,30)=0.11$, NS $)$ ] (Fig. 5). Furthermore, electromyography (EMG) measurements revealed that the sensory nerve conduction velocity (SNCV) differed significantly between genotypes $[\mathrm{F}(1,29)=7.31, \mathrm{p}<0.05]$; indeed, Gbxl $/$ - females had significantly increased SNCV $\left(\mathrm{t}_{14}=2.83, \mathrm{p}<0.05\right)($ Table 2$)$, as measured at the level of the caudal nerve. On the other hand, the latency and amplitude of the gastrocnemius muscle response evoked by sciatic nerve stimulation were comparable between genotypes $[\mathrm{F}(1,29)=1.63$, NS]

In summary, we used a variety of behavioral and electrophysiological phenotyping tests to evaluate sensory and motor functions in Gbxl mutant mice. Decreased exploratory behavior was found in the open field test and following immediate transfer during clinical observations. Exploration of the central part of the open field arena was significantly decreased in Gbxl-/- males and females, which might suggest increased anxiety in these mutants. However, this could also be due to the reduced locomotor activity of the mutants. Indeed, Gbxl-/- mice also showed decreased average speed with no significant effect on the distance travelled in the open field. Their altered gait during forward movement might explain the reduced speed and locomotor activity in the open field, which could not be attributed to defects in motor coordination or muscle strength. Abnormal gait may suggest proprioceptive-like deficits, as indicated by abnormal performance in beam walking, the test used for evaluation of proprioceptive functions, which was statistically significant only for Gbxl-/- females. Although no direct link can be clearly identified between motor deficits and sensory functions, we cannot exclude mutual interdependence of abnormal gait and sensory deficits indicated by reduced responses in hot plate test and increased SNCV, which were penetrant to a different degree in null-mutant males and females.

\section{Gbx1-/- mice do not show obvious hindbrain patterning defects}

Gbx genes are related to the Drosophila unplugged gene, which acts during development of the tracheal system, and for specification of neuroblast sublineages (Chiang et al. 1995; Cui \& Doe 1995). There are two Gbx genes in amniote species (human, mouse and chicken), as well as in zebrafish (Lin et al. 1996; Bouillet et al. 1995; Shamim \& Mason 1998; Niss \& Leutz 1998; Rhinn et al. 2003). Previous studies showed that in mouse, Gbx2 is involved in early specification of the midbrainhindrain boundary (MHB) organizer, a signaling center that will pattern the anterior hindbrain rhombomeres (Wassarman et al. 1997; Waters \& Lewandoski 2006; for review: Rhinn \& Brand 2001; Simeone 2000). In zebrafish it was shown 
that $g b x l$ acts during early positioning of the MHB, whereas $g b x 2$ functions at later stages, once the MHB is established (Rhinn $e t$ al. 2004; 2009; Burroughs-Garcia et al. 2011). In mouse, Gbxl is not expressed at the MHB as is the case during early zebrafish development. Its expression starts at E7.75 in the prospective hindbrain, spanning rhombomeres 2 to 7 during the segmentation phase (Rhinn et al. 2004; Waters, Wilson \& Lewandoski 2003). This suggested that Gbxl might be involved in early embryonic hindbrain patterning, which could underlie behavioral deficits associated with loss of Gbx1 function. To assess for possible rhombomeric abnormalities in Gbxl-/- mutants, we performed whole-mount in situ hybridizations at E9.5 with several markers, including Hoxb1 and Hoxa2. This analysis did not show any molecular or structural abnormality of the hindbrain rhombomeres in Gbxl-/- embryos (Supplementary material, Fig. S2). This suggests that $\mathrm{Gbx} 1$ is not required for early hindbrain patterning, in contrast to its mouse homologue Gbx2 (Wassarman et al. 1997; Waters \& Lewandoski 2006). Analysis of hindbrain derivatives (brain stem and cerebellum) at E18.5 using Gad67 as a differentiation marker also did not reveal any difference in Gbxl-/- versus wild-type mice (Supplementary material, Fig. S3).

\section{Development of the spinal cord dorsal horn in $G b x 1$ mutant mice}

At E12.5, the expression domains of $G b x 1$ and $G b x 2$ overlap, both being expressed in the ventricular and mantle zones of the dorsal spinal cord (Rhinn et al. 2004; Waters, Wilson \& Lewandoski 2003). As Gbx2 expression is downregulated after E12.5, both genes are only transiently coexpressed in dorsal spinal cord progenitor cells, and Gbxl is the only Gbx gene persistently expressed during later dorsal horn development (John, Wildner \& Britsch 2005).

Thus, the prominent expression of Gbxl in the dorsal horn could be relevant for the abnormal gait phenotype of adult Gbxl mutant mice, which led us to ask whether Gbxl is required for the maturation and/or specification of neurons of the dorsal horn during development. Nissl staining of E18.5 spinal cord sections revealed no obvious difference between the dorsal horn of wild-type and Gbxl-/- animals at thoraco-lumbar levels (Fig. 6A,B). Despite the clear behavioral phenotype, we were unable to identify any consistent alteration in the expression of several molecular markers of dorsal spinal cord cell populations in Gbxl-/- embryos. These markers included the genes encoding the transcription factors Lbxl (GrosS, Dottori \& Goulding 2002; Müller et al. 2002) (Fig. 6C,D), Lmxlb (Chen et al. 2001) (Fig. 6E,F) and the axon guidance molecule Netrin-1 (Leonardo et al. 1997) (Fig. 6G,H) analyzed at E12.5, 14.5, 16.5 and 18.5, and shown (Fig. 6) at E16.5.

\section{Projection pattern of primary sensory afferents in the dorsal horn of GbxI-/- mutants}

We examined the development of primary sensory afferent projections to the dorsal horn, which are well defined at E18.5, in Gbxl mutant mice. The projections of cutaneous nociceptive sensory neurons begin to invade the spinal grey matter by E12.5 (Ozaki \& Snider 1997). Immunostaining with an anti-calbindin-28K antibody at E16.5 and E18.5 marks a subset of cutaneous neurons and their afferent fibers (Honda 1995; Chen et al. 2001). By E18.5, calbindin+ fibers have invaded the dorsal horn of wild-type and Gbx1 mutants (Fig. 7A-B'). The Drg11 gene is required for the projection of cutaneous sensory afferent fibers to the dorsal spinal cord (Chen et al. 2001). In Gbx1-/- mutant mice, Drg11 expression was not affected in the dorsal horn at E12.5, 14.5, 16.5 or 18.5 (Fig. 7C,D and data not shown). Altogether, these data suggest that there are no defects in patterning of sensory afferent fiber projections to the dorsal horn, which selectively affects cutaneous afferents, although the markers used cannot rule out other types of patterning differences (for instance from primary afferents that do not label with calbindin). 
We further examined proprioceptive afferents at E18.5 by using antibodies to peripherin (Escurat et al. 1990). No consistent difference between wild-type and Gbxl-/-mice was observed at the level of proprioceptive fibers that extend toward motoneurons and interneurons in the deep dorsal horn, or at the level of fibers that enter into the spinal gray matter, at E18.5 (Fig. 7E,F) or E16.5 (Fig. 7G,H). During the revision of our manuscript, another Gbxl mutant allele was described (Buckley et al. 2013). In contrast to our observations and at a comparable stage, those mutants show disorganized peripherin expression, together with a decrease of Islet1-expressing cells in the ventral horn of the lumbar spinal cord (Buckley et al. 2013). This led us to analyze Islet1-expressing cells in ventral motor neurons in our Gbxl mutants. No differences in the number of Islet1+ cells within the lumbar ventral spinal cord were found at E14.5, E16.5 (Fig. S4) or E18.5 (data not shown). Thus, in contrast to the data of Buckley et al., our analysis does not suggest a defect in the assembly of the proprioceptive sensorimotor circuit. As the same Gbxl exon (exon 2) was targeted in both loss of function alleles, the reason for the phenotypic discrepancy remains unclear, although it should be mentioned that the mice might have different genetic backgrounds.

\section{Reduced GABAergic neuronal differentiation in Gbx1-/- mutants}

Gbxl is first expressed in the ventricular zone of the spinal cord at E11.5 (Rhinn et al. 2004 ; Waters, Wilson \& Lewandoski 2003). Then at E12.5-E13.5, it is broadly expressed in the mantle zone of the dorsal spinal cord. At E14 with the appearance of a distinguishable dorsal horn, Gbxl expression becomes more restricted. At E12.5, Gbxl is coexpressed with Lbxl; thus Gbxl cells correspond to class B neurons (John, Wildner \& Britsch 2005). As described in the introduction, late-born class B neurons comprise initially two populations, dILA and dILB. Because Gbxl neurons coexpress Lhxl/5 and Pax2, but not Lmxlb and Tlx3, it has been suggested that these neurons correspond to the dILA neuronal subtype (John, Wildner \& Britsch 2005). It has been shown that dILA neurons undergo GABAergic differentiation (Cheng et al. 2004), and as mature GABA+ neurons they continue expressing Gbxl (John, Wildner \& Britsch 2005). We therefore analyzed GABAergic neurons in the spinal cord of Gbxl-/- mutants, which we identified by expression of glutamic acid decarboxylase GAD67, an enzyme that regulates GABA synthesis. At E18.5, Gad67-expressing cells are found throughout the developing spinal cord of control mice (Somogyi et al. 1995). Importantly, Gad67 expression was reduced in the dorsal spinal cord of Gbxl mutant mice (Fig. 8A-D), i.e. there was a $16 \%$ decrease in the proportion of Gad67-expressing cells (Fig. 8I). This may reflect an abnormal development of GABAergic neurons, which in consequence coud lead to abnormal control of neuronal network in dorsal horn, possibly affecting inhibitory circuits throughout the spinal cord. This finding was strengthened by analysis of Pax2, another gene expressed in GABAergic cells in the spinal cord (Cheng et al. 2004), with cell countings corroborating the decrease in the proportion of GABAergic cells (Fig. 8E,F,I). Furthermore, it is know that during early post-natal period, the GABA pathway switches from excitatory to inhibitory in mouse (Ben-Ari et al. 2007). This shift was shown to occur within the two first weeks of age in hippocampal and spinal motor neurons in mouse (Stein et al. 2004) as well as in lamina I in rats (Sibilla \& Ballerini 2009). Also, it was mentioned that the switch depends on the species, sex, brain structures and neuronal types (Ben-Ari et al. 2007) and it was shown using a model system of cultured hippocampal neurons that the switch is triggered by GABAergic activity itself (Ganguly et al. 2001). Interestingly, when Gbx1-/pups were checked visually around weaning every day in the morning (analysis done on 5 litters, 42 pups, 8 Gbxl-/mutants), the locomotor deficits were first observed around post-natal days (P)16-17. Taking in account an eventual delay due to a diminished GABA activity, the appearance of the locomotion defect could coincide with the time point at which the GABA pathway switches from excitatory to inhibitory.

We also observed that Gad67 expression was unchanged in the brain stem and cerebellum of E18.5 Gbxl-/- mutants (Fig. S3), arguing against an involvement of these structures in the observed phenotype. 
We next addressed the question if the observed decrease of GABAergic cells is due to neuronal cell death or to a possible change of GABAergic to glutamatergic fate. TUNEL experiments were performed at various stages (E12.5, 14.5, 16.5, 18.5; Fig. 9 and data not shown). As expected, natural cell death occurs mainly in the developing spinal ganglia and ventral spinal cord (Fig. 9A,B; White et al. 1998) and natural cell death is suggested to be over by E15.5 (Fig. 9C,D; White et al. 1998). Our analysis showed no abnormal apoptosis in the dorsal spinal cord of Gbxl-/- mice (Fig. 9B,D). This finding would exclude that the decrease of Gad67-expressing cells is due to cell death, and suggest that Gbx1 is not required for cell survival. We then analyzed expression of Slc17a6, encoding VGLUT2, a vesicular glutamate transporter expressed in glutamatergic neurons (Kaneko et al. 2002). At E18.5, Slc17a6-expressing cells were increased in the dorsal spinal cord of Gbxl mutant mice (Fig. 8G,H). This finding suggests that part of the "missing" GABAergic cells may have differentiated into glutamatergic neurons.

Glutamate and GABA are the main neurotransmitters for excitatory and inhibitory neurons, respectively, in the vertebrate brain. These neurotransmitters are usually expressed in a mutually exclusive manner (Bellocchio et al. 2000; Fremeau et al. 2001). In the dorsal horn of the spinal cord, most ascending projection neurons and a subset of local circuit interneurons are excitatory and are glutamatergic. These neurons are modulated by local inhibitory neurons, many of which are GABAergic (for reviews: Melzack \& Wall 1965; Malcangio \& Bowery 1996; Dickenson 2002). Thus, GABA may inhibit transmitter release from primary afferent fibers. The output neurons of the dorsal horn are projection neurons, relaying sensory information to several brain areas. However, the majority of dorsal horn neurons are local circuit interneurons that do not project outside of the spinal cord. The output of projection neurons is influenced by local excitatory and inhibitory neurons (Todd 2010; Larsson \& Broman 2011; Guo et al. 2012). In Gbx1 mutants, the reduction in the proportion of GABAergic neurons, and the possible switch of some of these neurons to a glutamatergic identity, may disrupt neuronal circuitry, becoming phenotypically apparent at adult stages as measured by abnormal performance in several behavioral tests. Further electrophysiological studies will be necessary to link the decrease of GABAergic neurons to the abnormal gait observed in adult Gbxl mutant mice.

\section{Conclusion}

We have generated Gbxl-/- loss of function mutant mice, and investigated the development of the spinal cord dorsal horn in these mutants. Gbxl-/- mutants are viable and fertile, but display an altered gait during forward movement that specifically affects hindlimbs, beginning at post-natal days 16-17. This abnormal gait, documented by a series of behavioral tests, is not due to deficits in muscle strength or motor coordination. Although reduced performance of Gbxl-/- mice in beam walking, a test used in studies of proprioception, could potentially suggest proprioceptive deficits, such a hypothesis is not fully supported by at least two observations: (i) the incomplete penetrance of this phenotype because significant deficits were observed only in females, and (ii) by molecular data, which did not reveal deficits in the assembly of proprioceptive sensory afferents in the ventral or intermediate zone, described previously (Brown, 1981) as their target regions before contacting motoneurons.

Some of the deficits, such as altered sensory nerve conduction velocity, are significantly altered in females, whereas significant difference in hot plate performance was identified only in males. Although such differences could reflect sexual dimorphism, it is difficult to draw such a conclusion as definitive for two major reasons: (i) in some tests where a significant difference in performance was observed for one gender, the opposite gender may display a similar tendency, which remained non statistically significant; (ii) if for example females would be more prone to effects of Gbx1 mutation we could expect to find them less performant in different tests; however, the gender effects were inconsistent and concerned males or females depending on the measured parameter.

The spinal cord dorsal horn largely consists of inhibitory (GABAergic) and excitatory (glutamatergic) neurons that modulate somatosensory inputs from the periphery, including pain, temperature and mechanoception (Glasgow, 2005). Our analysis of major neuronal classes revealed a reduced proportion of GABAergic inhibitory interneurons expressing Gad67 in the superficial dorsal horn of Gbx1-/- mice. Gbx1 may therefore be functionally required for the differentiation of local inhibitory interneurons in the dorsal horn, corroborating a previous report of Gbxl expression in a specific subset of GABAergic neurons in this region of the spinal cord (John, Wildner \& Britsch 2005). Furthermore, 


\section{Acknowledgments}

440 We thank B. Schuhbaur for excellent technical assistance. We are grateful to Dr. K. Niederreither 441 for a critical reading of the manuscript, and to Drs. V. Brault, M. Paschaki and D. Dembélé for 442 help with statistical analysis. We thank Drs. C. Birchmeier, S. Britsch, F. Chen, K. Jagla, P. 443 Bouillet, B. Giros, P. Gruss, M. Tessier-Lavigne, R. Krumlauf and F. Rijli for the gift of reagents. 


\section{Figure Legends}

Figure 1. Inactivation of the mouse Gbxl gene by homologous recombination in embryonic stem (ES) cells. (A) The upper drawing shows the restriction map of the wild-type locus, boxes and lines corresponding to exons and introns, respectively. The homeodomain sequence is in red. In the targeting vector (below), two Gbxl genomic fragments (between the dashed lines) flank a lacZ reporter gene and the neomycin resistance gene (grey box), transcribed in the same orientation (thin arrow) as Gbxl. In the recombined locus (lower drawing), 313 bp of Gbxl exon 2 (including the homeodomain) are replaced by the lacZ neo sequence. The location of the $3^{\prime}$ probe used for Southern blot analysis of ES cells is indicated in blue, and the PCR primers used to distinguish wild-type and recombined alleles for genotyping of animals (F1, R1, LacZ R2; see Materials and methods) are also indicated. (B) Southern blot analysis of a targeted cell line (+/-) in comparison to wild-type (+/+) HM-1 ES cells, using a probe external to the targeting vector 3' homology arm. (C) Genotyping of wild-type (+/+), heterozygous (+/-) or homozygous mutant (-/-) mice by PCR amplification of fragments specific for the wild-type (354 bp) or mutated allele (269 bp), using the F1, R1 and LacZ R2 primers. (D,E) Anti-Gbx1 immunostaining. At E18.5, Gbx1 protein is absent in the spinal cord of Gbxl-/- mice (E), compared to wild- type (D). Scale bars: 100 $\mu \mathrm{m}$.

Figure 2. Abnormal phenotype of a 10 week-old $G b x 1$ - mouse when walking. Sequential pictures compare the normal gait of a wild-type mouse (A) and the abnormal gait ("duck-like" walk) of a Gbxl-/- mutant when walking (B). A movie of these mice is available (Supplementary Movie).

Figure 3. Effects of $G b x 1$ mutation on the latency and number of slips in the beam walking test. ** p $<0.01$ vs WT; Student t-test.

Figure 4. Open field performance of wild-type (WT) and Gbx1-/- mice. The distance traveled over the 20 min period of test reflects locomotor activity. The average speed was calculated during movement in the whole arena for the entire period of testing. Exploration of the central part of the open fied is expressed as the number of entries and percentage of time spent in the center. ${ }^{*} \mathrm{p}<0.05$ and $* * \mathrm{p}<0.01$ vs WT; Student t-test.

Figure 5. Startle reactivity and pre-pulse inhibition in wild-type (WT) and Gbxl-/- mice. Startle reactivity to background noise (65 dB), or to 70 , 80, 85, $90 \mathrm{~dB}$ acoustic stimulation, and startle reflex to a $110 \mathrm{~dB}$ stimulus, are presented. The percentage of pre-pulse inhibition of the startle response is displayed as a percentage of the pre-pulse intensity. WN, white noise; P, acoustic pulse intensity; ST, acoustic startle to $110 \mathrm{~dB}$; PP, pre-pulse intensity.

Figure 6. Absence of morphological and molecular abnormalities in the developing dorsal horn of Gbxl-/- mice. Sections through the spinal cord of wild-type (A,C,E,G) and Gbxl-/- (B,D,F,H) mice at E18.5 (A,B) and E16.5 (C-H) are shown. All sections are at the lumbar level. (A,B) Nisslstained sections. No differences are detectable between wild-type and mutants $(\mathrm{n}=3)$. In situ hybridizations for two transcription factor encoding genes, Lbx1 (C,D) and Lmxlb (E,F), and for the axon guidance molecule netrin-1 (G,H), are shown (n=3 for each marker). No differences are observed between wild-type and mutants. Scale bars: $100 \mu \mathrm{m}$.

Figure 7. Developmental progression of afferent projections in the dorsal horn of Gbxl-/- mice. (A-B') Anti-calbindin-D28K antibody staining. At E18.5, calbindin fibers have already entered the spinal gray matter in wild-type (A,A') and Gbxl-/- specimens (B,B'; n=3). Panels A', B' are higher magnifications of the areas boxed in A,B. (C,D) Expression of Drg11 in wild-type at E18.5 (C) and Gbxl mutant (D) mice. Mutant specimens were indistinguishable from wild-types (n=3). (E-H) Anti-peripherin antibody staining at E18.5 $(\mathrm{E}, \mathrm{F})$ and E16.5 (G,H). This staining reveals similar ingrowth of group IA muscle sensory afferents that grow to the ventral spinal cord (arrows) in wild-type (E,G) and mutant (F,H) ( $\mathrm{n}=3$ for each stage). Scale bars: $100 \mu \mathrm{m}\left(\mathrm{A}^{\prime}, \mathrm{B}^{\prime}: 50 \mu \mathrm{m}\right)$.

Figure 8. Abnormal GABAergic differentiation in Gbxl-/- mice. Expression of Gad67 in wild-type (A,C) and Gbxl-/- (B,D) mice at E18.5 (n=3). Higher magnification views (C,D; areas boxed in A,B) show the dorsal horn, in which cell countings were performed. Expression of Pax2 in wildtype (E) and Gbx1-/- (F) mice at E18.5 (n=3). Expression of Slc17a6 in wild-type (G) and Gbx1-/ (H) mice at E18.5 (n=3). (I) Countings (percentages of labelled vs total cells) revealed that the proportion of Gad67+ cells is diminished by $16 \%$ in Gbxl-/- mice (50.89\% \pm 2.61 Gad67+ 
cells in WT; $34.85 \% \pm 1.84$ in Gbx1-/- mice; Genotype $\mathrm{F}(1,4)=223.85$, *** $<<0.001$, Sections $\mathrm{F}(2,8)=2.22$, NS, Genotype*Sections $\mathrm{F}(2,8)=1.23$, NS). Also, the proportion of Pax2+ cells is diminished by $14.7 \%$ in Gbx1-/- mice (58.57\% $\pm 4,03$ Pax2+ cells in WT; $42.41 \% \pm 5.96$ in Gbx1-/ mice; Genotype $\mathrm{F}(1,4)=449.36$, ***p $<0.001$, Sections $\mathrm{F}(2,8)=3.34$, NS, Genotype*Sections $\mathrm{F}(2,8)=6.3$, $\mathrm{p}<0.05)$. In contrast, countings revealed that the proportion of Slc17a6+ cells is increased by $14.4 \%$ in Gbx1-/- mice (50.96\% \pm 1.84 Slc17a6+ cells in WT; $65.16 \% \pm 2.94$ in Gbx1-/- mice; Genotype $\mathrm{F}(1,4)=688.84$, ***p<0.001, Sections $\mathrm{F}(2,8)=1.004$, NS, Genotype*Sections $\mathrm{F}(2,8)=4.73$, $\mathrm{p}<0.05)$. Scale bars: $100 \mu \mathrm{m}$.

Figure 9. Examples of TUNEL labeling of lumbar spinal cord sections of wild-type (A,C) and Gbxl-/- (B,D) mice. Sections are shown at E12.5 (A,B) (n=3) and E18.5 (C,D) (n=3). Some TUNEL-labelled cells are seen in the dorsal root ganglia (drg) and in the ventral spinal cord (magnified in upper insets) at E12.5, in both wild-type and mutant. (E) Apoptotic cells in the interdigital mesenchyme of an E13.5 forelimb are shown as a positive control. Scale bars: $100 \mu \mathrm{m}$.

\section{Supplementary figure legends}

Figure S1. Expression analysis of Gbx2 in the developing spinal cord of Gbxl mutants. Sections through the spinal cord of wild-type (A,C,E,G) and Gbxl-/$(\mathrm{B}, \mathrm{D}, \mathrm{F}, \mathrm{H})$ mice are shown. All sections are at the lumbar level. In situ hybridizations for $G b x 2$ were performed at different developmental stages: E12.5 (A,B; n=2), E14.5 (C,D; n=2), E16.5 (E,F; n=3), and E18.5 (G,H; n=3). Scale bars: $100 \mu \mathrm{m}$.

Figure S2. Analysis of rhombomeric markers in Gbxl-/- embryos. Whole-mount in situ hybridizations of E9.5 embryos with 2 markers of prospective rhombomeres: Hoxb1, which labels rhombomere 4 (A,B; $\mathrm{n}=3$ ), and Hoxa2, which marks rhombomeres 2 to 6 and associated neural crest (C,D; $\mathrm{n}=3$ ). Scale bars: $50 \mu \mathrm{m}$.

Figure S3. In situ hybridization analysis of Gad67-expressing cells in the prenatal hindbrain. Sections are shown at various levels of the brain stem (A-F) and cerebellum $(\mathrm{G}, \mathrm{H})$ of wild-type (A,C,E,G; n=3) and Gbxl-/- (B,D,F,H; n=3) mice at E18.5. Scale bars: $100 \mu \mathrm{m}$.

Figure S4. Analysis of developing spinal cord motor neurons in Gbxl mutants. Expression of Islet1 in the lumbar spinal cord of wild-type (A,C) and Gbxl-/$(\mathrm{B}, \mathrm{D})$ mice at E14.5 (A,B; n=3) and E16.5 (C,D;n=3). (E) Countings revealed that the numbers of Islet1+ cells in the ventral horn are not significantly diminished in Gbx1-/- mice (at E14.5: 76 \pm 7.33 Islet1+ cells in WT; 75.22 \pm 3.13 in Gbx1-/- mice; Genotype F(1,4)=0.27, NS, Sections $\mathrm{F}(2,8)=0.18$, NS, Genotype*Sections $\mathrm{F}(2,8)=0.27$, NS; at E16.5: 22.38 \pm 5.96 Islet1+ cells in WT; 25.33 \pm 6.70 in Gbx1-/- mice; Genotype $\mathrm{F}(1,4)=3.03$, NS, Sections $\mathrm{F}(2,8)=4.73$, p<0.05, Genotype*Sections $\mathrm{F}(2,8)=5.46, \mathrm{p}<0.05)$. Scale bars: $100 \mu \mathrm{m}$.

Supplementary material : movie

Movie sequence showing 10 week-old $G b x I+/+$ and $G b x I-/-$ mice.

Table Captions

Table 1. Effects of $G b x 1$ mutation on body weight, basic neurological reflexes, specific motor abilities and pain sensitivity. Mice were analyzed at 10 weeks of age. Statistically different parameters in wild-type vs mutants appear in bold. * $\mathrm{p}<0.05$ and $* * \mathrm{p}<0.01$ vs wild-type; Student t-test.

Table 2. Effects of $G b x 1$ mutation on sensory nerve conduction velocity. The sensory nerve conduction velocity was measured at the level of the caudal nerve. The latency and the amplitude of gastrocnemius muscle response evoked by sciatic nerve stimulation were also recorded. $* \mathrm{p}<0.05$ vs wild-type; Student t-test. 
Bellocchio, E.E., Reimer, R.J., Fremeau, R.T., \& Edwards, R.H., (2000) Uptake of glutamate into synaptic vesicles by an inorganic phosphate transporter. Science, 289, 957-60. Ben-Ari, Y., Gaiarsa, J.L., Tyzio, R., \& Khazipov, R. , (2007) GABA: a pioneer transmitter that excites immature neurons and generates primitive oscillations. Physiological Review, 87, 121584.

Bermingham, N.A., Hassan, B.A., Wang, V.Y., Fernandez, M., Banfi, S., Bellen, H.J., Fritzsch, B., \&v Zoghbi, H.Y., (2001) Proprioceptor pathway development is dependent on Math1. Neuron, 30, 411-22.

Bouillet, P., Chazaud, C., Oulad-Abdelghani, M., Dollé, P., \& Chambon, P., (1995) Sequence and expression pattern of the Stra7 (Gbx-2) homeoboxcontaining gene induced by retinoic acid in P19 embryonal carcinoma cells. Developmental Dynamics, 204, 372-382.

Briscoe, J., \& Ericson, J., (1999) The specification of neuronal identity by graded Sonic Hedgehog signalling. Seminar Cell Developmental Biology, 10, 353-62.

Brown, A., (1981) Organisation in the spinal cord. New York : Springer.

Brown, S.D.M., Chambon, P., \& Hrabé de Angelis, M., (2005) EMPReSS: standardized phenotype screens for functional annotation of the mouse genome. Nature Genetics, 37, 1155.

Buckley, D.M., Burroughs-Garcia, J., Lewandoski, M., \& Waters, ST., (2013) Characterization of the gbx1(-/-) mouse mutant: a requirement for gbxl in normal locomotion and sensorimotor circuit development. PLoS One, 8(2):e56214.

Burroughs-Garcia, J., Sittaramane, V., Chandrasekhar, A., \& Waters, S.T., (2011) Evolutionarily conserved function of Gbx2 in anterior hindbrain development. Developmental Dynamics, 240, 828-38.

Caspary, T., \& Anderson, K.V., (2003) Patterning cell types in the dorsal spinal cord: what the mouse mutants say. Nature Reviews Neuroscience, 4, 289-9.

Chen, Z.F., Rebelo, S., White, F., Malmberg, A.B., Baba, H., Lima, D., Woolf, C.J., Basbaum, A.I., \& Anderson, D.J., (2001) The paired homeodomain protein DRG11 is required for the projection of cutaneous sensory afferent fibers to the dorsal spinal cord. Neuron, 31, 59-73.

Cheng, L., Arata, A., Mizuguchi, R., Qian, Y., Karunaratne, A., Gray, P.A., Arata, S., Shirasawa, S., Bouchard, M., Luo, P., Chen, C.L., Busslinger, M., Goulding, M., Onimaru, H., \& Ma, Q., (2004) Tlx3 and Tlxl are post-mitotic selector genes determining glutamatergic over GABAergic cell fates. Nature Neuroscience, 7, 510-7.

Chiang, C., Young, K.E., \& Beachy, P.A., (1995) Control of Drosophila tracheal branching by the novel homeodomain gene unplugged, a regulatory target for genes of the bithorax complex. Development, 121, 3901-12.

Chotteau-Lelièvre, A., Dollé, P., \& Gofflot F., (2006) Expression analysis of murine genes using in situ hybridization with radioactive and nonradioactively labeled RNA probes. Methods Molecular Biology, 326, 61-87. 
549 Cui, X., \& Doe, C.Q., (1995) The role of the cell cycle and cytokinesis in regulating neuroblast

550 sublineage gene expression in the Drosophila CNS. Development, 121, 3233-43.

551 Dickenson, A.H., (2002) Gate control theory of pain stands the test of time. British Journal of

552 Anaesthia, 88, 755-7.

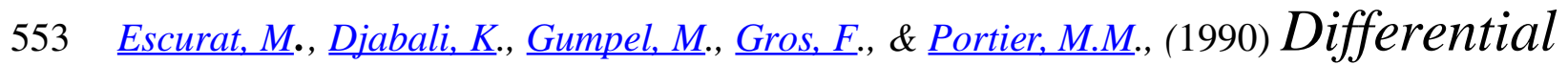

554 expression of two neuronal intermediate-filament proteins,

555 peripherin and the low-molecular-mass neurofilament protein

556 (NF-L), during the development of the rat. Journal of Neuroscience, 10, 764-

55784.

558 Fremeau, R.T., Troyer, M.D., Pahner, I., Nygaard, G.O., Tran, C.H., Reimer, R.J., Bellocchio,

559 E.E., Fortin, D., Storm-Mathisen, J., \& Edwards, R.H., (2001) The expression of vesicular

560 glutamate transporters defines two classes of excitatory synapse. Neuron, 31, 247-60.

561 Glasgow, S. M., (2005) Ptfla determines GABAergic over glutamatergic neuronal cell fate in the spinal cord dorsal

562 horn. Development, 132, 5461-5469.

563 Goulding, M., Lanuza, G., Sapir, T., \& Narayan, S., (2002) The formation of

564 sensorimotor circuits. Current Opinion Neurobiology, 12, 508-15.

565 Gowan, K., Helms, A.W., Hunsaker, T.L., Collisson, T., Ebert, P.J., Odom, R., \&

566 Johnson, J.E., (2001). Crossinhibitory activities of Ngnl and Math1 allow

567 specification of distinct dorsal interneurons. Neuron, 31, 219-32.

568 Graham, B.A., Brichta, A.M., \& Callister, R.J., (2007) Moving from an averaged to specific

569 view of spinal cord pain processing circuits. Journal of Neurophysiology, 98, 1057-63.

570 Gross, M.K., Dottori, M., \& Goulding, M., (2002) Lbxl specifies somatosensory

571 association interneurons in the dorsal spinal cord. Neuron, 16, 535-49.

572 Guo, Z., Zhao, C., Huang, M., Huang, T., Fan, M., Xie, Z., Chen, Y., Zhao, X.,

573 Xia, G., Geng, J., \& Cheng, L., (2012) Tlx1/3 and Ptfl a control the expression of

574 distinct sets of transmitter and peptide receptor genes in the developing dorsal

575 spinal cord. Journal of Neuroscience, 32, 8509-20.

576 Hatcher, J.P., Jones, D.N.C., Rogers, D.C., Hatcher, P.D., Reavill, P.D., Hagan, J.J., \& Hunter, A.J., (2001) Development of

577 SHIRPA to characterize the phenotype of gene-targeted mice. Behaviour Brain Research, 125, 43-47.

578 Helms, A.W., \& Johnson, J.E., (2003) Specification of dorsal spinal cord

579 interneurons.

580 Current Opinion Neurobiology, 13, 42-9.

581 Honda, CN., (1995) Differential distribution of calbindin-D28k and parvalbumin in

582 somatic and visceral sensory neurons. Neuroscience, 68, 883-92. 
Hu, J., Huang, T., Li, T., Guo, Z., \& Cheng, L. (2012) cMaf Is Required for the Development of Dorsal Horn

Laminae III/IV Neurons and Mechanoreceptive DRG Axon Projections. Journal of Neuroscience, 32, $5362-5373$.

Irwin, S., (1968) Comprehensive observational assessment: Ia. A systematic, quantitative procedure for assessing the behavioral and physiologic state of the mouse. Psychopharmacologia, 13, 222-257.

John, A., Wildner, H., \& Britsch, S., (2005) The homeodomain transcription factor Gbxl identifies a subpopulation of late-born GABAergic interneurons in the developing dorsal spinal cord. Developmental Dynamics, 234, 767-71. Kaneko, T,\& Fujiyama, F., (2002) Complementary distribution of vesicular glutamate transporters in the central nervous system. Neuroscience Research, 42, 243-50.

Larsson, M., \& Broman, J., (2011) Synaptic plasticity and pain: role of ionotropic glutamate receptors. Neuroscientist, 17, 256-73.

Lee, K.J., \& Jessell, T.M., (1999) The specification of dorsal cell fates in the vertebrate central nervous system. Annual Reviews Neuroscience, 22, 261-94.

Leonardo, E.D., Hinck, L., Masu, M., Keino-Masu, K., Fazeli, A., Stoeckli, E.T., Ackerman, S.L., Weinberg, R.A., \& Tessier-Lavigne, M., (1997) Guidance of developing axons by netrin-1 and its receptors. Cold Spring Harb Symp Quant Biol, 62, $467-78$.

Le Mouellic, H., Lallemand, Y., \& Brûlet, P., (1990) Targeted replacement of the homeobox gene Hox-3.1 by the Escherichia coli lacZ in mouse chimeric embryos. Proceedings of the National Academy of Sciences U S A , 87, 4712-6.

Lewis, K.E., (2006) Do genes regulate simple behaviours? Understanding how different neurons in the vertebrate spinal cord are genetically specified. Philosophical Transactions of the Royal Society London B Biological Science, 361, 45-66.

Lin, X., Swaroop, A., Vaccarino, F.M., Murtha, M.T., Haas, M., Ji, X., Ruddle, F.H., \& Leckman, J.F., (1996) Characterization and sequence analysis of the human homeobox-containing gene GBX2. Genomics, 31, 335-342.

Malcangio, M., \& Bowery, N.G., (1996) GABA and its receptors in the spinal cord. Trends in Pharmacological Sciences, 17, 457-62.

Magin, T.M., McWhir, J., \& Melton, D.W., (1992) A new mouse embryonic stem cell line with good germ line contribution and gene targeting frequency. Nucleic Acids Research, 20, 3795-6.

Melzack, R., \& Wall, P.D., (1965) Pain mechanisms: a new theory. Science, 150, 971-9. Müller, T., Brohmann, H., Pierani, A., Heppenstall, P.A., Lewin, G.R., Jessell, T.M., \& Birchmeier, C., (2002) The homeodomain factor lbxl distinguishes two major programs of neuronal differentiation in the dorsal 
618 Nagy, A., Gertsenstein, M., Vintersten, K., \& Behringer, R., (2003) Manipulating the Mouse 619 Embryo: A Laboratory Manual. Cold Spring Harbor Laboratory Press, New York.

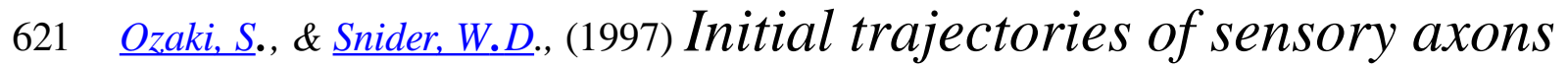
622 toward laminar targets in the developing mouse spinal cord. 623 Journal of Comparative Neurology, 380, 215-29.

624 Rexed, B., (1952) The cytoarchitectonic organization of the spinal cord in the cat. 625 Journal of Comparative Neurology, 96, 414-95.

626 Ramírez-Solis, R., Davis, A.C., \& Bradley, A., (1993) Gene targeting in embryonic 627 stem cells. Methods Enzymology, 225, 855-78.

628 Rebelo, S., Reguenga, C., Lopes, C., \& Lima, D., (2010). Prrxl1 is required for the generation of 629 a subset of nociceptive glutamatergic superficial spinal dorsal horn neurons. Developmental 630 Dynamics, 239, 1684-94.

631 Rhinn, M., \& Brand, M., (2001) The midbrain-hindbrain boundary organizer. Current Opinion 632 Neurobiology, 11, 34-42.

633 Rhinn, M., Lun, K., Amores, A., Yan, Y.L., Postlethwait, J.H., \& Brand, M., (2003) Cloning, 634 expression and relationship of zebrafish gbxl and gbx2 genes to Fgf signaling. Mechanisms of 635 Development, 120, 919-36.

636 Rhinn, M., Lun, K., Werner, M., Simeone, A., \& Brand, M., (2004) Isolation and 637 expression of the homeobox gene Gbxl during mouse development. Developmental 638 Dynamics, 229, 334-9.

639 Rhinn, M., Lun, K., Ahrendt, R., Geffarth, M., \& Brand, M., (2009) Zebrafish gbxl refines the 640 midbrain-hindbrain boundary border and mediates the Wnt8 posteriorization signal. Neural 641 Development, 2, 4-12.

642 Robertson, E. J., (1987). Embryo-derived stem cell lines. In Teratocarcinomas and Embryonic 643 Stem Cells : a Practical Approach. (ed. E. J. Robertson). Oxford, England: IRL Press. pp. 71-112.

644 Shamim, H., \& Mason, I., (1998) Expression of Gbx-2 during early development of the chick embryo. Mechanisms of Development, 76, 157-159.

645 Simeone, A., (2000) Positioning the isthmic organizer where Otx2 and Gbx2 meet. Trends in 646 Genetics, 16, 237-40.

647 Somogyi, R., Wen, X., Ma, W., \& Barker, J.L., (1995) Developmental kinetics of GAD family $648 m R N A s$ parallel neurogenesis in the rat spinal cord. Journal of Neuroscience, 15, 2575-91.

649 Todd, A.J., (2010) Neuronal circuitry for pain processing in the dorsal horn. Nature 650 Reviews Neuroscience, 11, 823-36.

651 Wassarman, K.M., Lewandoski, M., Campbell, K., Joyner, A.L., Rubenstein, J.L., 652 Martinez, S., \& Martin, G.R., (1997) Specification of the anterior hindbrain and 
653 establishment of a normal mid/hindbrain organizer is dependent on Gbx2 gene

654 function. Development, 124, 2923-3.

655 Waters, S.T., Wilson, C.P., \& Lewandoski, M., (2003) Cloning and embryonic

656 expression analysis of the mouse Gbxl gene. Gene Expression Patterns, 3, 313-7.

657 Waters, S.T., \& Lewandoski, M., (2006) A threshold requirement for Gbx2 levels in hindbrain 658 development. Development, 133,1991-2000.

659 White, F.A., Keller-Peck, C.R., Knudson, C.M., Korsmeyer, S.J., and Snider, W.D. (1998)

660 Widespread elimination of naturally occurring neuronal death in Bax-deficient mice. Journal of 661 Neuroscience, 18,1428-39.

662 Willis, W., \& Coggeshall, R.E., (1991) Sensory mechanisms of the spinal cord. Plenum Press, NY. 


\section{Table $\mathbf{1}_{\text {(on next page) }}$}

Effects of Gbxl mutation on body weight, basic neurological reflexes, specific motor abilities and pain sensitivity.

Mice were analyzed at 10 weeks of age. Statistically different parameters in wild-type vs mutants appear in bold. $* \mathrm{p}<0.05$ and ${ }^{* *} \mathrm{p}<0.01$ vs wild-type; Student t-test. 


\section{Table 1:}

\begin{tabular}{|c|c|c|c|c|}
\hline & \multicolumn{2}{|c|}{ Males } & \multicolumn{2}{|c|}{ Females } \\
\hline & Wild-type & Gbx1-/- & Wild-type & Gbx1-/- \\
\hline Body weight (g) & $26.57 \pm 0.73$ & $25.40 \pm 0.48$ & $19.81 \pm 0.32$ & $20.88 \pm 0.89$ \\
\hline Gait (\% abnormal) & 0 & $43 \% * *$ & 0 & $63 \% * *$ \\
\hline $\begin{array}{l}\text { Short-term locomotor activity } \\
\text { (number of squares crossed in } 30 \\
\text { s) }\end{array}$ & $26.70 \pm 1.37$ & $\begin{array}{l}19.71 \pm \\
1.39 * *\end{array}$ & $28.33 \pm 1.00$ & $\begin{array}{c}22.00 \pm \\
1.57 * *\end{array}$ \\
\hline Rotarod- 4 to $40 \mathrm{rpm}$ in $5 \mathrm{~min}(\mathrm{~s})$ & $\begin{array}{c}123.87 \pm \\
17.56\end{array}$ & $\begin{array}{c}95.11 \pm \\
15.08 \\
\end{array}$ & $\begin{array}{c}116.33 \pm \\
9.10\end{array}$ & $\begin{array}{c}130.25 \pm \\
14.99\end{array}$ \\
\hline \multirow{2}{*}{$\begin{array}{l}\text { Grip strength } \\
\text { (adjusted to body } \\
\text { weight })(g) \\
\end{array}$} & $3.97 \pm 0.18$ & $4.00 \pm 0.24$ & $3.75 \pm 0.17$ & $3.38 \pm 0.26$ \\
\hline & $8.30 \pm 0.24$ & $7.72 \pm 0.37$ & $7.00 \pm 0.24$ & $7.22 \pm 0.54$ \\
\hline Hot plate (s) & $13.43 \pm 1.26$ & $\begin{array}{c}17.13 \pm \\
1.08 * \\
\end{array}$ & $12.72 \pm 1.15$ & $15.03 \pm 1.63$ \\
\hline
\end{tabular}




\section{Table 2 (on next page)}

Effects of Gbxl mutation on sensory nerve conduction velocity.

The sensory nerve conduction velocity was measured at the level of the caudal nerve. The latency and the amplitude of gastrocnemius muscle response evoked by sciatic nerve stimulation were also recorded. $* \mathrm{p}<0.05$ vs wild-type; Student t-test. 
2 Table 2 :

\begin{tabular}{lccccc}
\hline & \multicolumn{2}{c}{ Males } & \multicolumn{2}{c}{ Females } \\
\hline & Wild-type & Gbx1-/- & Wild-type & Gbx1-/- \\
\hline $\begin{array}{l}\text { Sensory nerve conduction } \\
\text { velocity }(\mathbf{m} / \mathbf{s})\end{array}$ & $70.33 \pm 1.70$ & $72.20 \pm 1.53$ & $63.93 \pm 2.35$ & $\begin{array}{c}\mathbf{7 1 . 8 1} \pm \\
\mathbf{1 . 5 0 *}\end{array}$ \\
\hline $\begin{array}{l}\text { Gastrocnemius } \\
\text { M-wave }\end{array}$ & Latency $(\mathrm{ms})$ & $0.93 \pm 0.06$ & $0.91 \pm 0.06$ & $0.99 \pm 0.08$ & $0.84 \pm 0.05$ \\
\cline { 2 - 6 } & Amplitude $(\boldsymbol{m V})$ & $43.99 \pm 3.15$ & $44.60 \pm 5.87$ & $46.46 \pm 6.70$ & $55.41 \pm 6.03$ \\
\cline { 2 - 6 } & & & & &
\end{tabular}




\section{Figure 1}

Inactivation of the mouse Gbxl gene by homologous recombination in embryonic stem (ES) cells.

(A) The upper drawing shows the restriction map of the wild-type locus, boxes and lines corresponding to exons and introns, respectively. The homeodomain sequence is in red. In the targeting vector (below), two Gbxl genomic fragments (between the dashed lines) flank a lacZ reporter gene and the neomycin resistance gene (grey box), transcribed in the same orientation (thin arrow) as Gbxl. In the recombined locus (lower drawing), 313 bp of Gbxl exon 2 (including the homeodomain) are replaced by the lac $Z$ neo sequence. The location of the 3' probe used for Southern blot analysis of ES cells is indicated in blue, and the PCR primers used to distinguish wild-type and recombined alleles for genotyping of animals (F1, R1, LacZ R2; see Materials and methods) are also indicated. (B) Southern blot analysis of a targeted cell line (+/-) in comparison to wild-type (+/+) HM1 ES cells, using a probe external to the targeting vector 3' homology arm. (C) Genotyping of wildtype (+/+), heterozygous (+/-) or homozygous mutant (-/-) mice by PCR amplification of fragments specific for the wild-type (354 bp) or mutated allele (269 bp), using the F1, R1 and LacZ R2 primers. (D,E) Anti-Gbx1 immunostaining. At E18.5, Gbx1 protein is absent in the spinal cord of Gbxl-/- mice (E), compared to wild- type (D). Scale bars: $100 \mu \mathrm{m}$. 


\section{Figure 2}

Abnormal phenotype of a Gbx1-/- mouse when walking.

Sequential pictures compare the normal gait of a wild-type mouse (A) and the abnormal gait ("ducklike" walk) of a Gbxl-/- mutant when walking (B). A movie of these mice is available (Supplementary Movie).
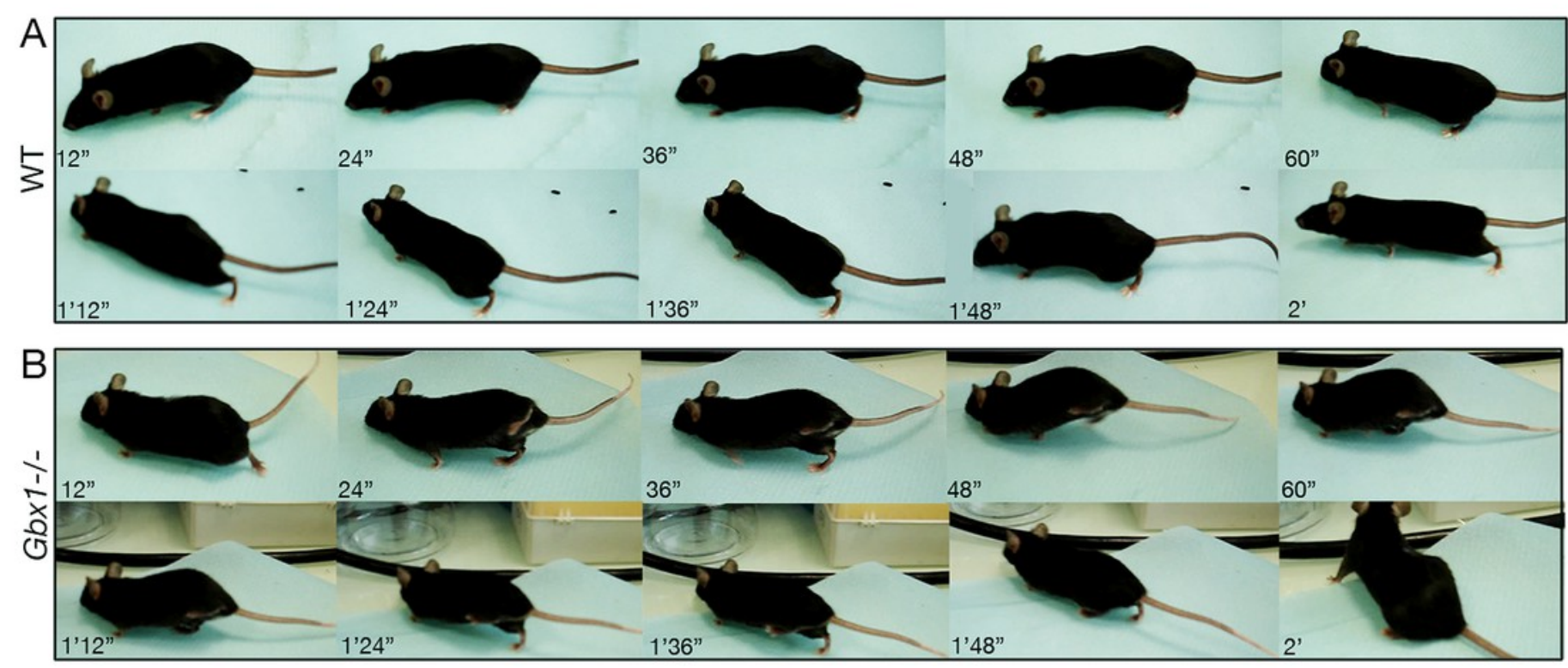


\section{Figure 3}

Effects of Gbxl mutation on the latency and number of slips in the beam walking test.

** $\mathrm{p}<0.01$ vs WT; Student t-test.
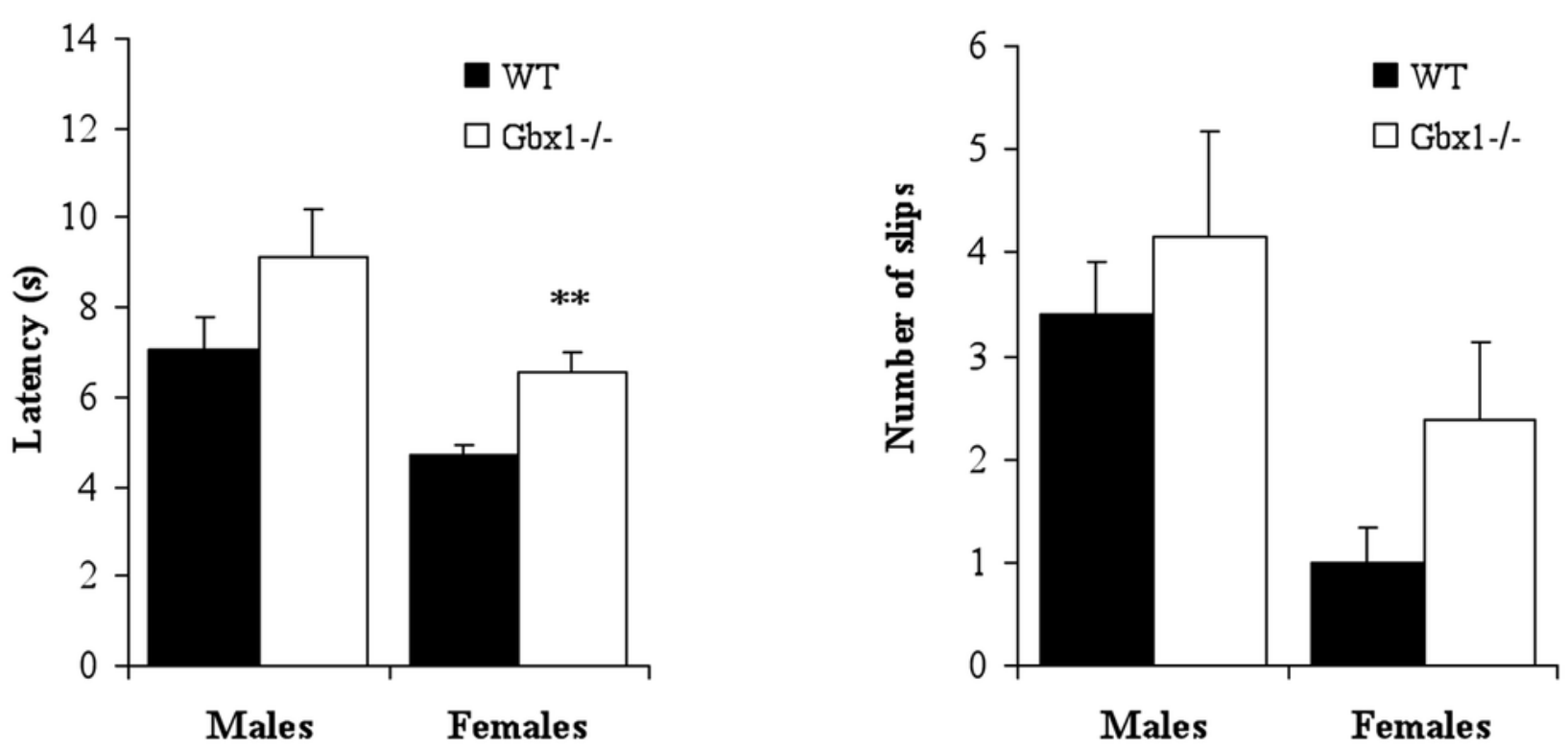


\section{Figure 4}

Open field performance of wild-type (WT) and Gbxl-/- mice.

The distance traveled over the $20 \mathrm{~min}$ period of test reflects locomotor activity. The average speed was calculated during movement in the whole arena for the entire period of testing. Exploration of the central part of the open fied is expressed as the number of entries and percentage of time spent in the center. ${ }^{*} \mathrm{p}<0.05$ and ${ }^{* *} \mathrm{p}<0.01$ vs WT; Student t-test.
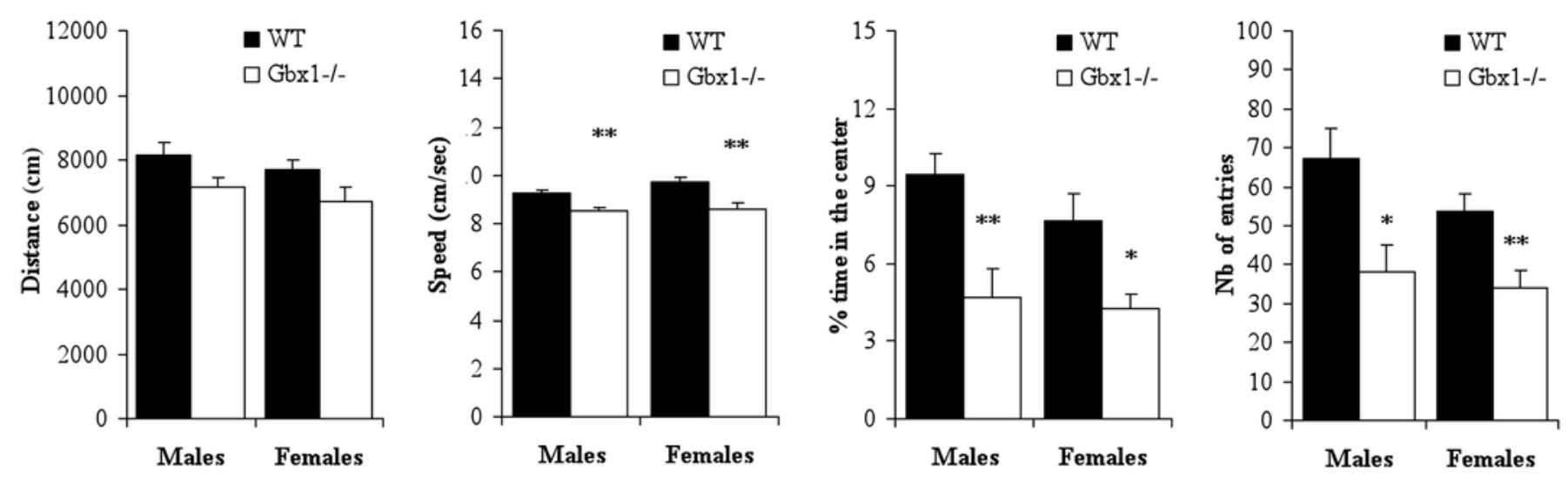


\section{Figure 5}

Startle reactivity and pre-pulse inhibition in wild-type (WT) and Gbxl-/- mice.

Startle reactivity to background noise $(65 \mathrm{~dB})$, or to $70,80,85,90 \mathrm{~dB}$ acoustic stimulation, and startle reflex to a $110 \mathrm{~dB}$ stimulus, are presented. The percentage of pre-pulse inhibition of the startle response is displayed as a percentage of the pre-pulse intensity. $\mathrm{WN}$, white noise; $\mathrm{P}$, acoustic pulse intensity; ST, acoustic startle to $110 \mathrm{~dB}$; PP, pre-pulse intensity.

Acoustic startle

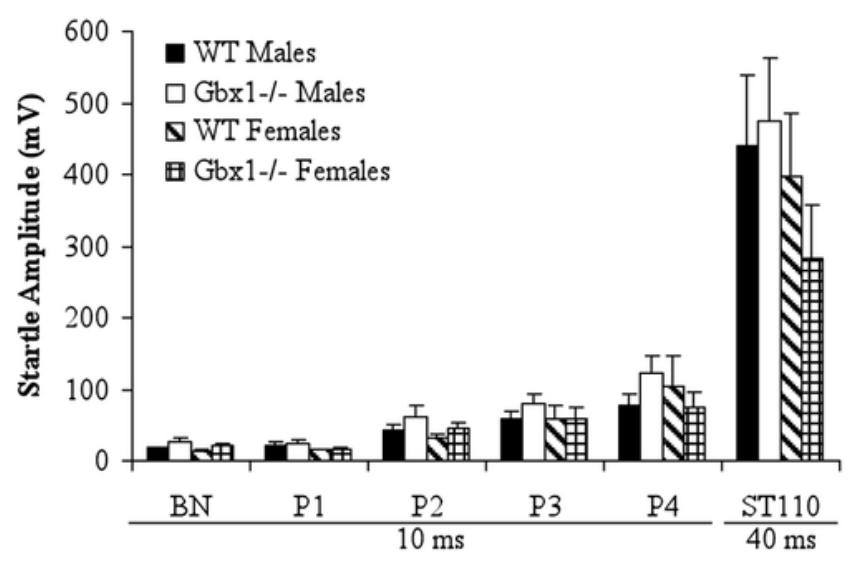

Sensorimotor

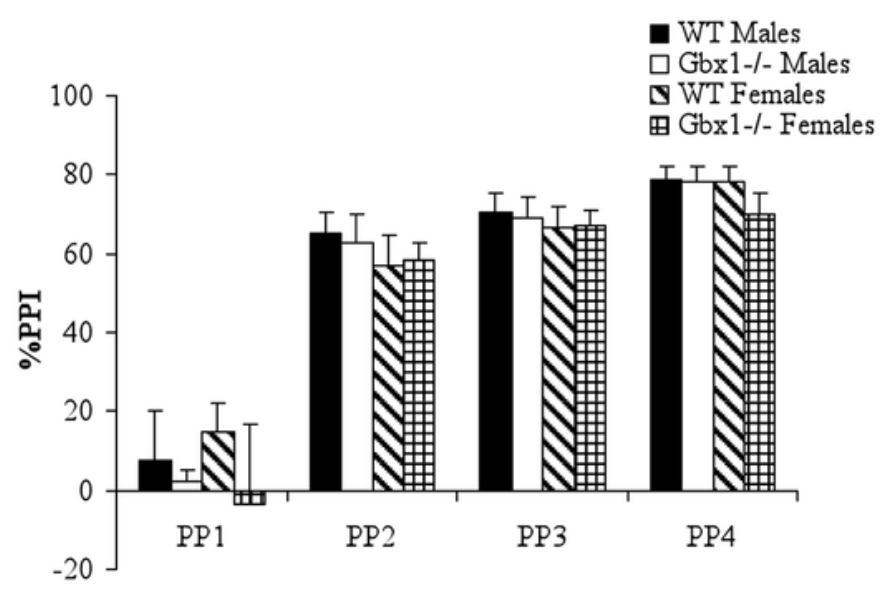




\section{Figure 6}

Absence of morphological and molecular abnormalities in the developing dorsal horn of Gbxl-/mice.

Sections through the spinal cord of wild-type (A,C,E,G) and Gbxl-/- (B,D,F,H) mice at E18.5 (A,B)

and E16.5 (C-H) are shown. All sections are at the lumbar level. (A,B) Nissl-stained sections. No differences are detectable between wild-type and mutants $(n=3)$. In situ hybridizations for two transcription factor encoding genes, $\operatorname{Lbx} 1(\mathbf{C , D})$ and $\operatorname{Lmx} 1 b(\mathbf{E}, \mathbf{F})$, and for the axon guidance molecule netrin-1 $(\mathbf{G}, \mathbf{H})$, are shown ( $\mathrm{n}=3$ for each marker). No differences are observed between wild-type and mutants. Scale bars: $100 \mu \mathrm{m}$. 


\section{Figure 7}

Developmental progression of afferent projections in the dorsal horn of Gbxl-/- mice.

(A-B') Anti-calbindin-D28K antibody staining. At E18.5, calbindin fibers have already entered the spinal gray matter in wild-type (A,A') and Gbxl-/- specimens $\left(\mathrm{B}, \mathrm{B}^{\prime} ; \mathrm{n}=3\right)$. Panels $\mathrm{A}^{\prime}, \mathrm{B}^{\prime}$ are higher magnifications of the areas boxed in A,B. (C,D) Expression of $\mathrm{Drg} 11$ in wild-type at E18.5 (C) and Gbx1 mutant (D) mice. Mutant specimens were indistinguishable from wild-types (n=3). (E-H) Antiperipherin antibody staining at E18.5 (E,F) and E16.5 (G,H). This staining reveals similar ingrowth of group IA muscle sensory afferents that grow to the ventral spinal cord (arrows) in wild-type (E,G) and mutant $(\mathrm{F}, \mathrm{H})\left(\mathrm{n}=3\right.$ for each stage). Scale bars: $100 \mu \mathrm{m}\left(\mathrm{A}^{\prime}, \mathrm{B}^{\prime}: 50 \mathrm{~mm}\right)$. 


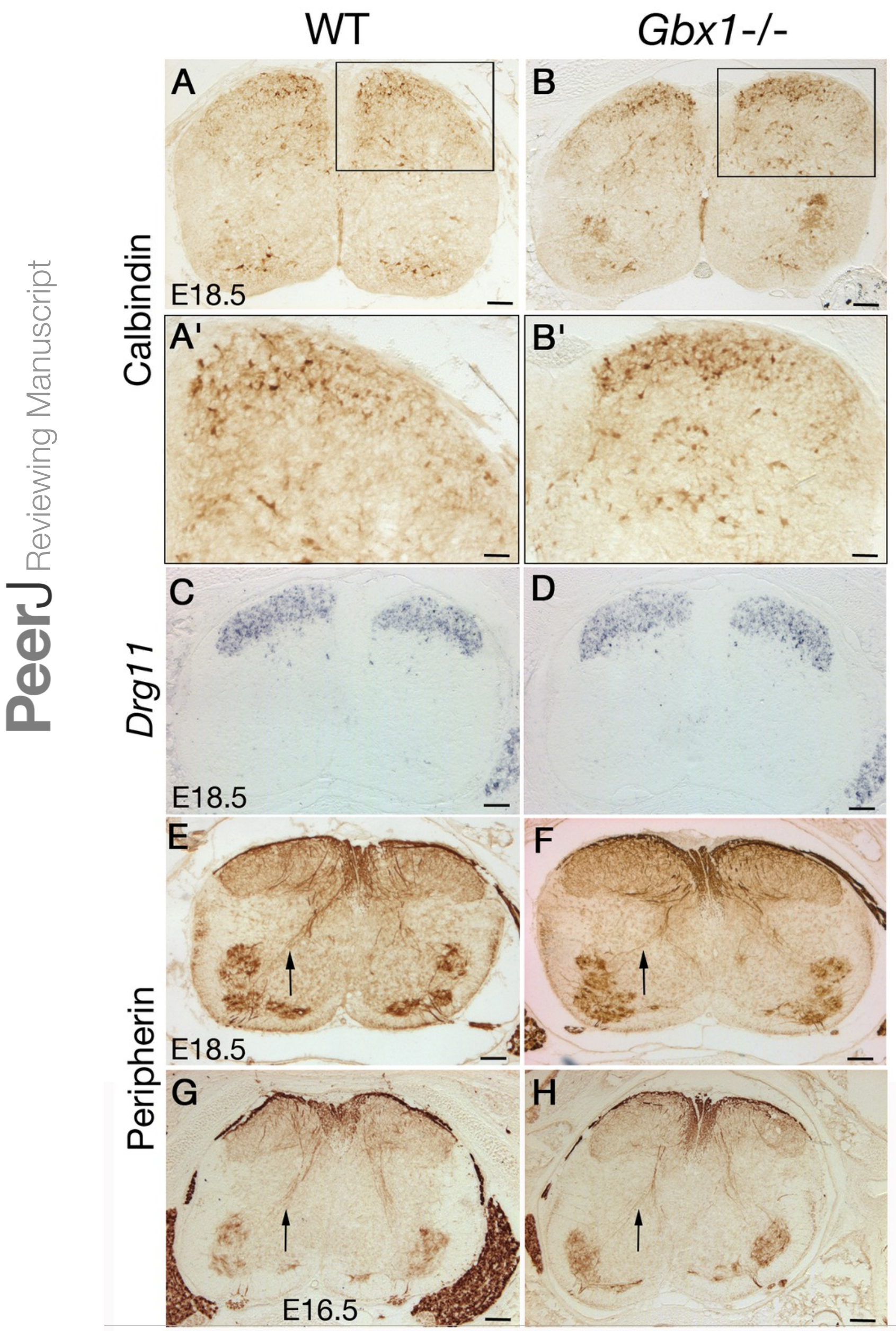

PeerJ reviewing PDF | (v2012:11:45:4:2:ACCEPTED 13 Aug 2013) 


\section{Figure 8}

Abnormal GABAergic differentiation in Gbxl-/- mice.

Expression of Gad67 in wild-type (A,C) and Gbx1-/- (B,D) mice at E18.5 (n=3). Higher magnification views (C,D; areas boxed in A,B) show the dorsal horn, in which cell countings were performed. Expression of Pax2 in wild-type (E) and Gbx1-/- (F) mice at E18.5 (n=3). Expression of Slc17a6 in wild-type (G) and Gbx1-/- (H) mice at E18.5 (n=3). (I) Countings (percentages of labelled vs total cells) revealed that the proportion of Gad67+ cells is diminished by $16 \%$ in Gbxl-/- mice $(50.89 \%$ \pm 2.61 Gad67+ cells in WT; $34.85 \% \pm 1.84$ in Gbxl-/- mice; Genotype $\mathrm{F}(1,4)=223.85,{ }^{* * *} \mathrm{p}<0.001$, Sections $F(2,8)=2.22$, NS, Genotype*Sections $F(2,8)=1.23$, NS). Also, the proportion of Pax $2+$ cells is diminished by $14.7 \%$ in Gbx1-/- mice (58.57\% $\pm 4,03$ Pax2+ cells in WT; $42.41 \% \pm 5.96$ in Gbx1-/mice; Genotype $\mathrm{F}(1,4)=449.36, * * * \mathrm{p}<0.001$, Sections $\mathrm{F}(2,8)=3.34$, NS, Genotype*Sections $\mathrm{F}(2,8)=6.3, \mathrm{p}<0.05)$. In contrast, countings revealed that the proportion of Slc17a6+ cells is increased by $14.4 \%$ in Gbxl-/- mice $(50.96 \% \pm 1.84$ Slc17a6+ cells in WT; $65.16 \% \pm 2.94$ in Gbx1-/- mice; Genotype $\mathrm{F}(1,4)=688.84, * * * \mathrm{p}<0.001$, Sections $\mathrm{F}(2,8)=1.004$, NS, Genotype*Sections $\mathrm{F}(2,8)=4.73$, $\mathrm{p}<0.05)$. Scale bars: $100 \mu \mathrm{m}$. 


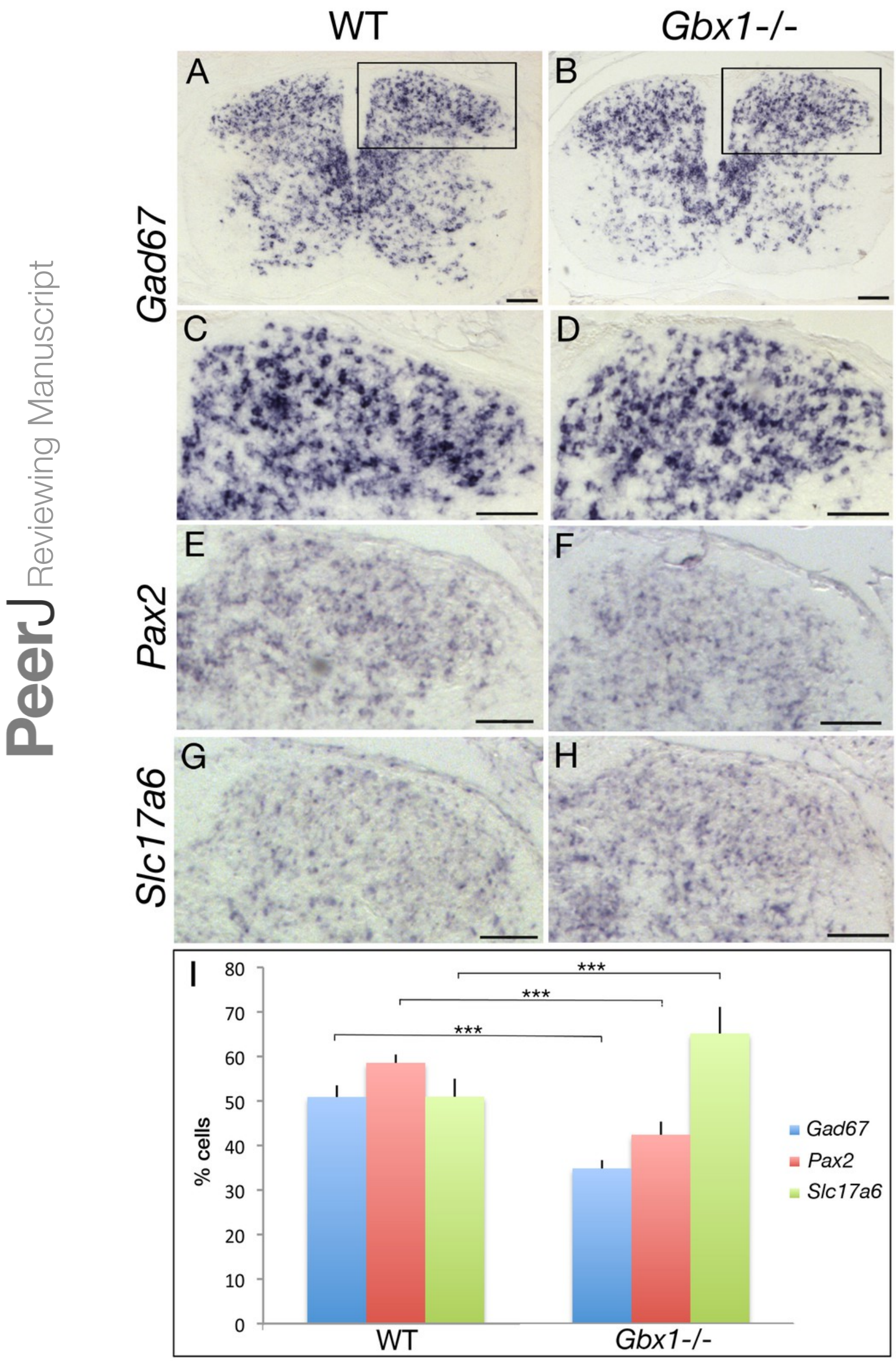




\section{Figure 9}

Examples of TUNEL labeling of lumbar spinal cord sections of wild-type (A,C) and Gbxl-/$(\mathrm{B}, \mathrm{D})$ mice.

Sections are shown at E12.5 $(A, B)(n=3)$ and E18.5 $(C, D)(n=3)$. Some TUNEL-labelled cells are seen in the dorsal root ganglia (drg) and in the ventral spinal cord (magnified in upper insets) at E12.5, in both wild-type and mutant. (E) Apoptotic cells in the interdigital mesenchyme of an E13.5 forelimb are shown as a positive control. Scale bars: $100 \mu \mathrm{m}$. 


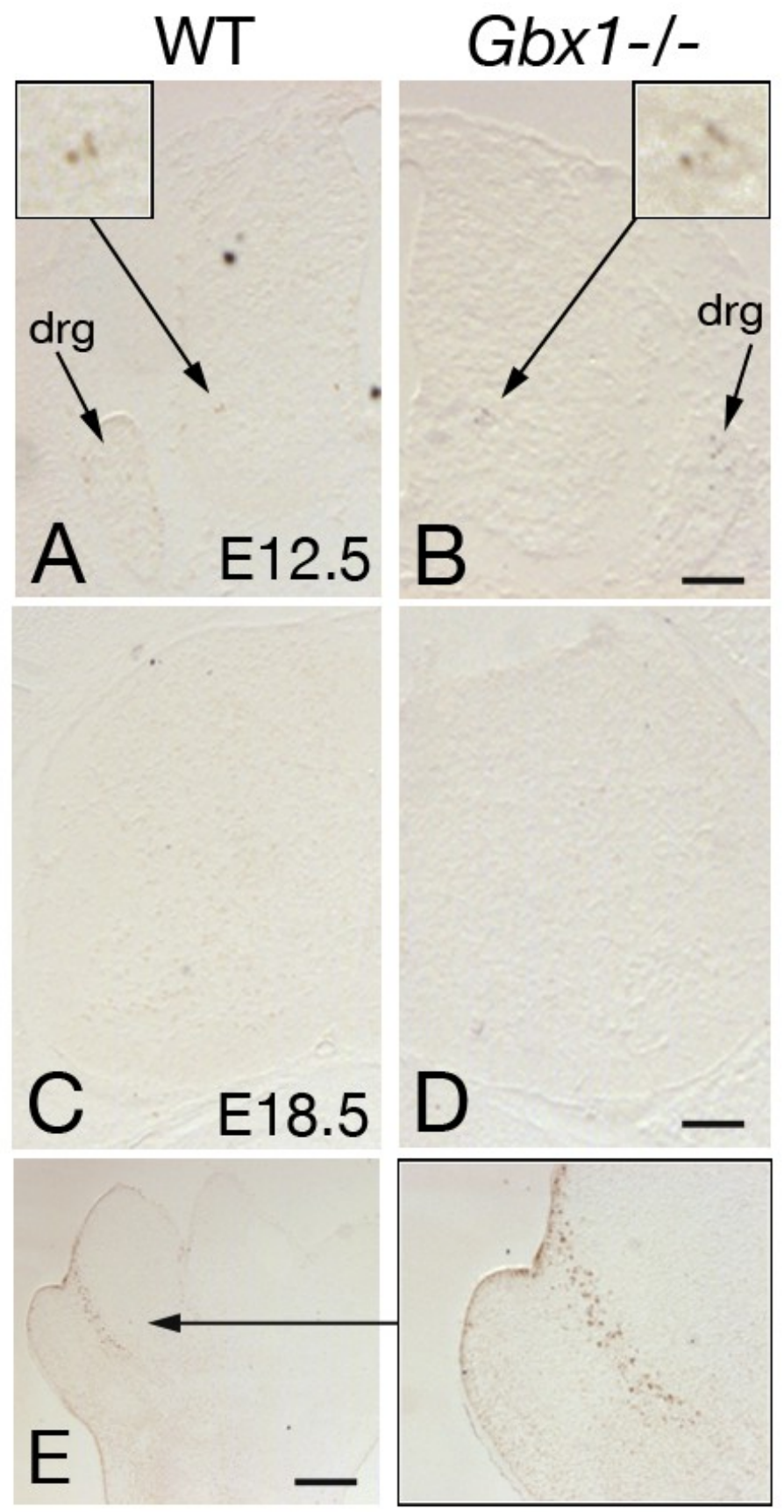

